\title{
Teodoro Ardemans en la obra del Ayuntamiento de Toledo (1695-1703)
}

\author{
antonio José diaz Fernández *
}

El ayuntamiento de Toledo está considerado como un edificio singular dentro de nuestra historia de la arquitectura; ante todo, como una obra renacentista cuyo estudio definitivo ha realizado Fernando Marías manejando una precisa documentación y reparando en las partes construidas en torno al año de $1700^{\prime}$. También es cierto que algunos historiadores del Arte español han destacado mínima y vagamente la obra de época barroca en la que se dice intervino el arquitecto Teodoro Ardemans, pero acusándose aún muchas imprecisiones que parece poner en orden recientemente Diego Suárez al nombrar a Ardemans como autor en concreto de las trazas de escalera y cuerpo superior de las torres con su chapitel ${ }^{2}$.

Sin embargo, no encontramos valoradas las dimensiones de la actuación del arquitecto madrileño ni la de los maestros de obras toledanos, aún más ignorada, quienes trabajaron en la empresa constructiva propiciando una trama de relaciones de carácter profesional, mediatizadas por la institución municipal, que nos sitúa en el verdadero hecho de la edificación y construcción del ayuntamiento toledano. Desde la abundante documentación conservada en el Archivo Municipal, estamos en condiciones de precisar el alcance real de las propuestas barrocas y el grado de autoría de Ardemans en las mismas. Nuestro interés se dirige principalmente a la obra del bloque interior, constituido por su acceso principal y sus dos salas de sesiones; y en lo exterior, a la fachada norte y a las dos torres chapiteladas que rematan el frente, configurando su definitiva

- Licenciado Historia del Arte.

Mafías Franco, Fernando, La Arquitectura del Renacimiento en Toledo (1541-1631). Madrid, CSIC-IPIET, 1986, t. IV., págs. 4 y ss.

SuÁRez Quevedo, Diego, "Período Barroco", en Arquitecturas de Toledo. Toledo, Consejería de Educación y Cultura, 1991, t. II, pág. 33. 
imagen arquitectónica desde comienzos del siglo XVIII (fig. 1). Obra éstas, realizadas en los años finales del siglo anterior dentro de presupuestos artísticos formalmente barrocos pero que inciden sobre un grandioso edificio renancentista preexistente que, en puridad, se reducía a su magnífica fachada de cantería, planteada por Juan de Herrrera en 1575 y concluida en 1618 por Jorge Manuel Teotocópuli ${ }^{3}$.

Las fechas que enmarcan el tiempo de duración de lo que podemos llamar la terminación barroca del ayuntamiento de Toledo quedan plasmadas conmemorativamente en dos tableros marmóreos que lucen en el testero de la escalera y nos señalan el inicio en 1690, bajo el reinado de Carlos II, y en 1700, con la nueva dinastía borbónica, la conclusión ${ }^{4}$. Son, pues, trece los años empleados para proseguir y acabar una obra que realmente se hallaba inconclusa desde que en 1618 se terminase de alzar la mencionada fachada oriental con lonja y torres sólo hasta la cornisa ${ }^{5}$.

El emplazamiento del ayuntamiento se hizo sobre un solar que resultaba estrecho y con poco fondo cuando se acometen a fines del siglo XVII las obras de reconstrucción del interior del edificio. Se trataba de un espacio rectangular, con orientación norte-sur, cuya fachada principal ocupa el lado este, ante la plaza, y dos menores: la meridional, que salva en altura el desnivel de la calle; y la septentrional, que recibe la única entrada al edificio. Aunque Herrera dejó planteadas las dependencias interiores, esta idea no fue más allá del acondicionamiento del espacio longitudinal dado por las galerías y los cubos de las torres; actuando, incluso, sobre una fábrica anterior, formada por las salas y otras piezas, a la que se antepuso la fachada en piedra y que fueron integradas en el conjunto interior del edificio. Tal es el caso de la pared intermedia que divide las salas de las galerías, en la que se descubrió recientemente una portada mudéjar de ladrillo ${ }^{6}$; otro sí, algunas de las estancias contiguas a la torre meridional, en las que se advierten modos constructivos

3 Marias, F., Op. cit., t. IV, pág. 5 .

4 Parro, Sixto R., Toledo en la mano. (Toledo, 1857). ed. facsímil. Toledo, IPIET, 1978, t. II, pág. 536. Impulsaron la obra, sucediéndose en el cargo de corregidor, D. Francisco de Vargas, Marqués de Vargas, D. Carlos Ramírez de Arellano, Conde de Murillo, D. Martín de Basurto, Marqués de Castrosena, y D. Alonso Pacheco, Conde de Ibangrande.

5 Marias, F. Op. cit., t. IV, pág. 5.

- Santacruz Sánchez de Rojas, G., "Misterio y trascendencia de la puerta descubierta en las casas consistoriales", Toletum, XVII, 1985, pág. 9. Si hemos de pensar en ese arco como en la portada principal del antiguo consistorio u otra casa notable, el proyecto de Herrera aprovechó el espacio delantero, avanzando sobre la recién allanada plaza, para ampliar el exiguo sitio del viejo edificio y usó el muro de la portada como columna vertebral de la nueva planta; pared que también se conservó en 1695 


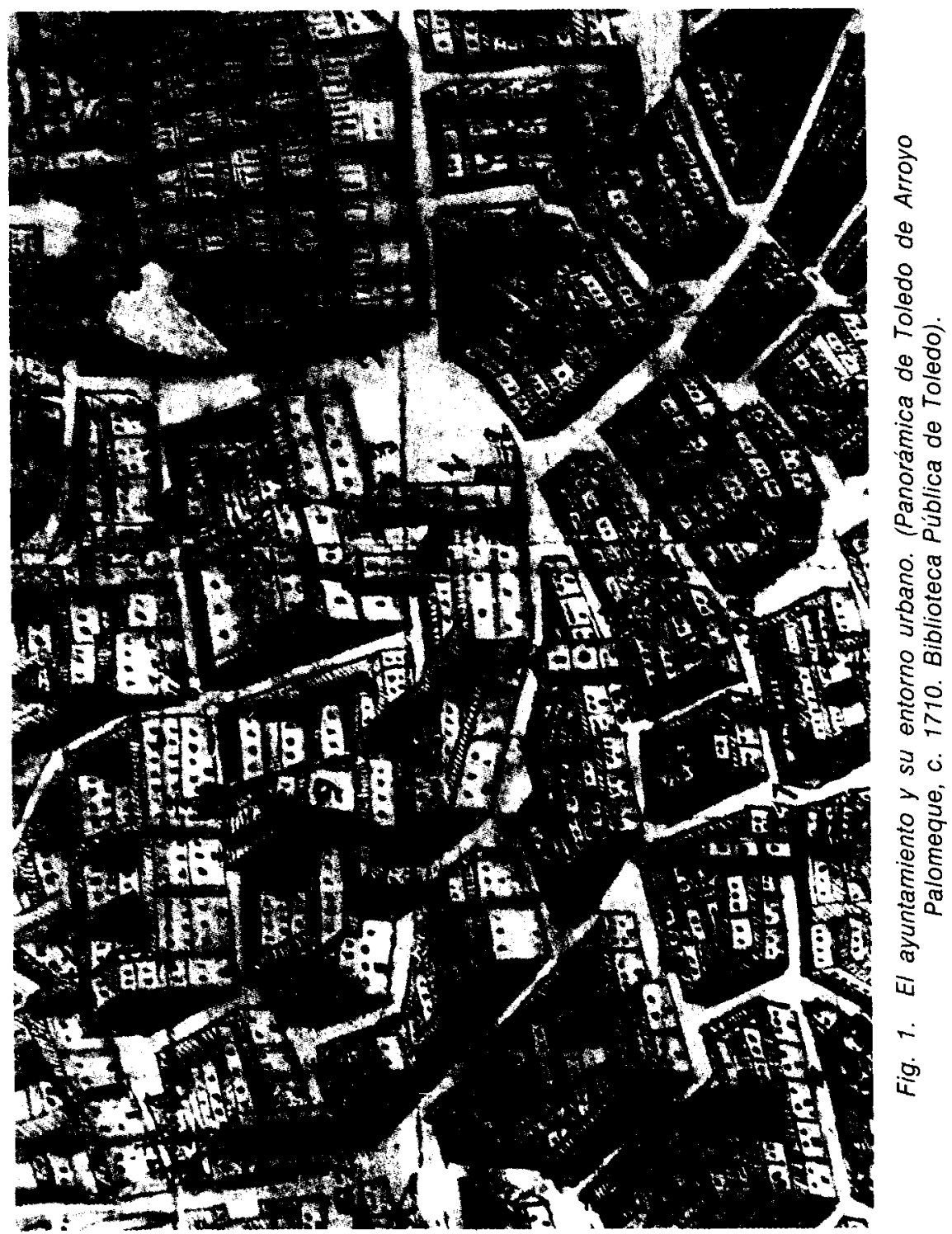


de fines del siglo $\mathrm{x} v$, y nacela con epigrafía gótica, que hacían pensar al historiador Parro ser los uúnicos restos que aún quedan (con la parte de edificio que le cae debajo en ese costado meridional) de la fábrica primitiva, se hubieron de labrar ya en el reinado de los Reyes Católicos salas y oficinas para el Ayuntamiento; todo lo que ahora existe, a excepción de la pequeña parte que hemos insinuado, ha sido edificado desde el siglo XVII acá, y es obra de diferentes veces emprendida, ejecutada a trozos...” ${ }^{7}$.

El suelo municipal edificado limitaba en 1690 con dos calles públicas confluyentes en la plaza, mientras que el lado occidental formaba medianería con casas que ahogaban la posibilidad de su engrandecimiento interior. Sin embargo, la disponibilidad de suelo para ensanchar la fábrica se consigue con la adquisición entre 1695 y 1696 de las «tiendas nuevas", propiedad de las Monjas de Santo Domingo el Antiguo, y del "corralillo", que pertenecía a la casa de la Dignidad Arzobispal; en superficie, $358 \mathrm{~m}^{2}$ y $205 \mathrm{~m}^{2}$ respectivamente ${ }^{8}$. La amenaza de ruina del interior, constituido por las dos viejas salas superpuestas, se trataba de reparar desde 1690 por el Maestro Mayor y alarifes de la ciudad, que veían en el desplome del muro exterior u occidental la causa del hundimiento de la sala alta y su repercusión sọbre la inferior ${ }^{9}$. De este modo, en diciembre de 1694 el maestro arquitecto Pedro González propuso medidas para realizar el apeo definitivo de la estructura, tanto en las dos salas como en el portal que las precedia, afectado de humedades ${ }^{10}$. La inminente ruina de las salas capitulares, y la de todo el edificio interior en sí, revelaba la inconsistencia de las reparaciones parciales llevadas a cabo durante la segunda mitad del siglo XVII y actualizaba la necesidad de completar la fachada con una sólida arquitectura interior acorde con la representatividad y dignidad del capítulo municipal como órgano gubernativo de la ciudad.

\section{LA OBRA DEL AYUNTAMIENTO: ARQUITECTOS Y PROYECTOS}

En esta situación, el Ayuntamiento acordaba en 5 de noviembre de 1694 que los comisarios de obras nombrados al efecto, junto con los

PARRO, S.R., Op. cit., t. II, pág. 532.

- ARChivo MUNICIPAL DE TOledo (AMT), Sección Obras. Caja: Obras de ayuntamiento (16901799). Cuaderno con los expedientes de compra de unas casas (1965-96). No está foliado (s/f).

9 AMT, Obras de Ayuntamiento (1690-1799). "Primer Cuaderno (1695-1697)". Diversos documentos cronológicamente dispuestos que tratan de la obra interior $(\mathbf{s} / \mathbf{f})$. Queda citada su fecha en el texto.

10 AMT, ibidem. 
maestros y alarifes locales, estudien la obra a realizar ${ }^{11}$. Después de setenta y siete años sin actividad constructiva de envergadura, la reconstrucción interior de las casas de Ayuntamiento es examinada por los caballeros y señores comisarios Don Luis Lasso de la Vega, Don Manuel Fernández de Madrid, como regidores; Don Gabriel Alonso de Buendía y Don Francisco de Segovia Villalba, como jurados, designados para intervenir en la empresa edilicia a la luz de dos proyectos principales: el uno, de raigambre local y el otro, de filiación madrileña.

El primero de ellos, firmado en Toledo en 20 de enero de 1695, lo presentaba Pedro González, Maestro Mayor de Obras de los Reales Alcázares y Aparejador de la obra de la Santa Iglesia, adjuntando un pliego con las trazas - corte de las salas y alzado exterior del muro de cerramiento- (fig. 2) ${ }^{12}$. González proponía en sus condiciones levantar un muro nuevo de albañilería con sus machos de ladrillo, de mayor a menor, y cajones de mampostería, aparejado todo con cal y verdugados, atendiendo a "como va demostrado por el diseño de la traça»; hacer una sala baja engrosando los muros algo más de un metro y cubriendo con envigado de madera y bovedillas, y, encima, otra sala de muros más delgados, aconsejando que "si ser pudiera que tenga tanto alto como ancho tien la dicha sala, quedará en buena proporçión". La cubrición se haría con armadura de parhilera con sus cuatro limatesas y jabalcones, colocando buhardillas; el techo, con un encamonado y alistonado que dejase un cielo raso con media caña cóncava y su filete de resalto. Todo el interior de ambas salas recibiría un jaharrado y blanqueado final «cumpuniendo los solados y los chapeados de açulejos".

Estas son las directrices del proyecto de Pedro González en el que sin duda plantea, dentro de una manera tradicional de construir y con un conocimiento correcto de la teórica y práctica de la albañilería, un edificio sin grandes pretensiones arquitectónicas, con poco desarrollo en altura y una evidente falta de proporcionalidad armoniosa en las salas. Por este plan el maestro percibió - y por sus honorarios se puede calibrar su rango profesional- 120 reales de vellón ${ }^{13}$.

Por otra parte, Don Teodoro Ardemanus, que con este nombre firma en los documentos municipales, como "Architecto y maestro mayor de

' AMT, ibidem.

12 En una equivalencia de 1 pie $=0,28 \mathrm{~m}$, la pared que se habia de construir mediria 30,5 m de longitud y 12,5 de altura, aproximadamente; obra calificada de "dilatada", su coste se calculaba en 77.000 reales.

13 AMT, Obras de ayuntamiento (1690-1799). «Primer Cuaderno (1695-1697)». 


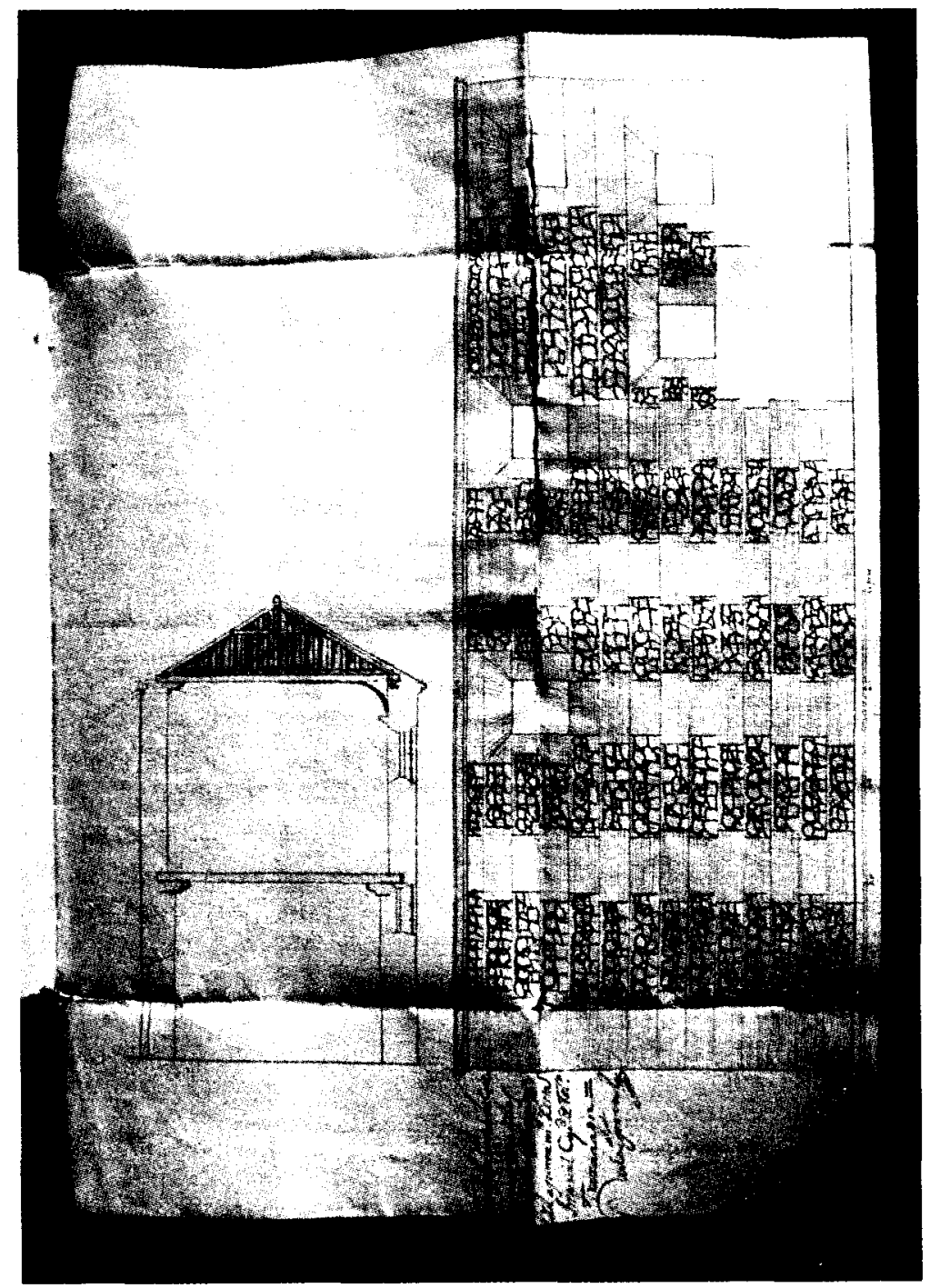

Fig. 2. Trazas para muro y salas, por Pedro González (1695). 
obras residente en Madrid", signaba una declaración fechada en 3 de abril del mismo año acerca de la uobra de las salas alta y baja donde se zelebran los ayuntamientos de esta ciudad de Toledo" ${ }^{14}$. En sus consideraciones apuntaba, previa demolición de la armadura y artesonado de la sala superior y tras el desmonte de toda la pared de poniente, levantar en una línea de 129 pies de longitud ( 36 metros aproximadamente) un nuevo muro de epilares de ladrillo y berdugos y cajones yntermedios de mampostería de piedra y cal", con un grueso mayor hasta el primer suelo y algo menor hasta la altura de cubrición. Proponía una esquina de sillares, de mayor y menor, para el ángulo noroeste y para el alero recomendaba hacer canecillos de madera con su vuelo «llevando su roçadura, cobija y ristel y quarto bocel con dos filetes". Entendía, asimismo, la necesidad de reforzar la pared intermedia preexistente, cuya fábrica se respetaba, con almas de madera en toda su altura para asegurar el apoyo de soleras y vigas de los suelos. Para cubrir el edificio diseñaba una parhilera bien jabalconada y con tres buhardas. Para el interior de la sala alta pensó en un techo o bóveda encamonada cuyo esquilfe habría de llevar relievados lunetos, fajas y contrafajas "que demuestra su planta y corte", arrancando desde "su cornisa capitelada reciviendo unos tambanillos à las fajas principales". Proponía igualmente que ambas salas "hayan de quedar blanqueadas de yeso blanco y paño" y el solado con «baldosa de Higares o Mozejón», raspada y cortada ${ }^{15}$.

En estos puntos principales el arquitecto esbozaba la concepción general de la obra, acompañando dos trazas adjuntas de planta superior y sección de las salas (fig. 3). Obra, sin duda, de mayor compromiso arquitectónico y estético y con un planteo más acertado de las proporciones al concebir una mayor altura de la edificación, incluso por encima del nivel de la fachada oriental, y mejor acondicionamiento lumínico de la sala alta. Sin embargo, la compartimentación de la planta no se define, avisando que en lo que se "a de executar en lo que forma oratorio se dexe su capacidad hasta que para ello se execute demostrazión de su forma", reservándose asi el dibujo de esta pieza menor, fácil de encajar en el bloque de la edificación; también, con respecto al testero exterior norte, aconseja apear la ventana, la portada y la escalera, obradas en piedra, para que una vez replanteada esta fachada se restituyesen para componer el acceso principal. A modo de advertencia, el propio Ardemans, en una de sus condiciones finales previene «que se haya de executar dicha obra

14 AMT, ibidem.

15 Higares es paraje del término municipal de Mocejón, a unos $12 \mathrm{~km}$ de Toledo en dirección $\mathrm{N}$ en donde existieron tejares. 

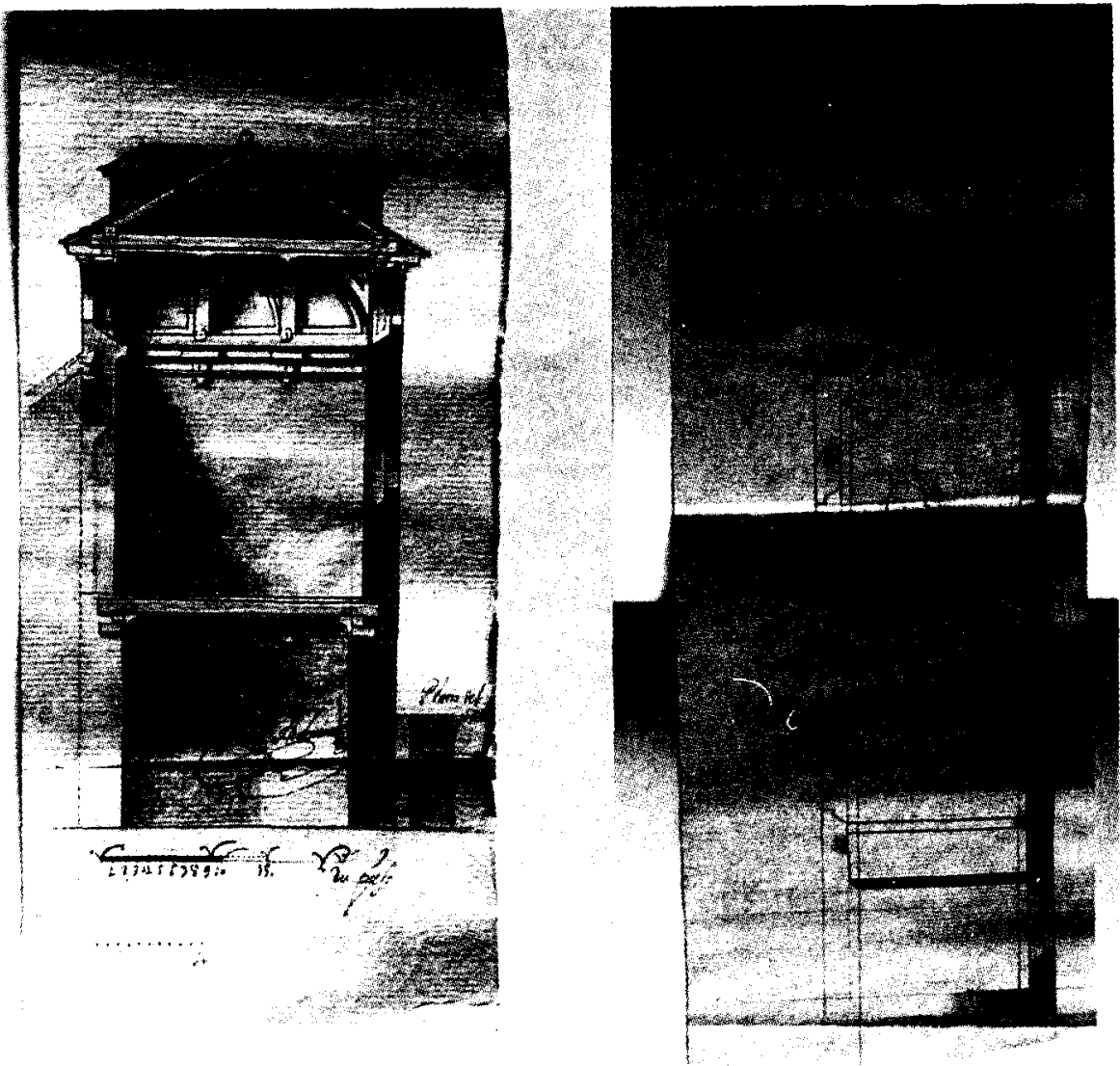

Fig. 3. Planta y corte, por Teodoro Ardemans (1695).

arreglándose à la planta y corte hecho por Theodoro Ardemanus y que para alguna innovación se le dé al dicho quenta para su disposición» ${ }^{16}$.

En respuesta, en el ayuntamiento de 4 de abril de 1695 se acordó, vistas las trazas del maestro madrileño, encargar las diligencias pertinentes a la comisión de obras "valiéndose para la execución de toda ella del dicho maestro mayor Dn. Theodoro Ardemanus que ha ejecutado las condiciones y planta para dicha obra que se ha visto en este ajuntamiento y

${ }^{16}$ AMT, Obras de ayuntamiento (1690-1799). “Primer Cuaderno (1695-1697)". 
de los demás maestros que elijieren y les pareziere conviniente todo ello a disposizión de dichos Cavalleros Comisarios" y buscando «lo más conviniente a la autoridad de la Ciudad, hermosura seguridad y perpetuydad de dicha obra" ${ }^{17}$. A los mismos comisarios compete el que a Ardemans «le hagan el agasajo y regalo que les pareziere conviniente por el trabajo y ocupazión que ha tenido en el reconocimiento de dicha obra planta, traça, condiziones que para ella ha executado", y en 7 de ese mes se le abonan 344 reales $^{18}$.

Sin embargo, el proyecto de edificación interior del consistorio se revisa nuevamente a la luz de las deficiencias estructurales que van revelando los derribos previos, a los que asiste con su dirección ya desde 31 de mayo el que es "maestro maior de la Sta. Iglesia de esta ciudad de Toledo y de las obras de la Villa de Madrid" ${ }^{19}$. Tras el reconocimiento introduce nuevas observaciones proponiendo, primeramente, la demolición también de la pared intermedia, que por ser de tierra se hallaba ruinosa y además "dará más sitio para agrandar la pieças en su ancho, de calidad que no se tomare nada de la casa medianera"; seguidamente, el apeo, bajo la torre norte, de la escuadra "del archivo" que mira a noroeste hasta el mismo macho de la esquina; y, finalmente, el cambio de la escalera, colocándola "en el sitio que la Ziudad ha con agrado, que en él cave la escalera muy vien y se consigue dejar la entrada del zaguán más decente y la escalera quedará más suave ${ }^{20}$. De esta forma, al plan inicial se añaden estas propuestas que, indudablemente, suponian una reconsideración y revalorización arquitectónica del proyecto en el que a la prevista edificación de las salas se suma ahora el replanteo del portal de entrada con su escalera.

En ese mismo año, a primero de junio, los maestros Ardemans y González son convocados a la comisión de ayuntamiento, presidida por el corregidor Don Carlos Ramírez de Arellano, en la que se habría de decidir sobre el plan inmediato de la obra. La postura de los capiturales es la de secundar el parecer de Ardemans en todo lo ya formulado así como en la necesidad de ampliar la edificación «pues en fábrica que haze Toledo deve ser en la maior suntuosidad, no teniendo por ynconveniente el que dure la fábrica uno, dos o tres años más» ${ }^{21}$. La reedificación seguía siendo

AMT, ibidem.

is AMT, Obras de ayuntamiento (1690-1799). "Cuaderno de Cuentas de 1695 a 1700". Aquí las partidas se relacionan por orden cronológico (s/f).

19 AMT, Obras de ayuntamiento (1690-1799). "Primer Cuaderno (1695-1697)".

20 AMT, ibidem.

${ }^{21}$ AMT, ibidem. 
el asunto de continuas sesiones municipales en las que se decantará el proyecto, definitivamente perfilado desde 5 de junio de 1695 con la participación de Pedro González, maestro mayor de obras, y la asesoría de los maestros de albañilería toledanos Juan Díaz Aldeano, Matías Gutiérrez y Antonio Pérez, encargados de la realización práctica de la obra desde el primer momento ${ }^{22}$. Los cuatro trataron la forma en que se habrían de fabricar las dos salas, teniendo ya demolidas las viejas, y cómo reparar la pared intermedia y su prolongación en la del archivo, teniendo presentes las declaraciones y plantas efectuadas por el propio González (en 20 de enero) y por Teodoro Ardemans (en 3 de abril y 31 de mayo). Pero, además, se prevenía la posibilidad de edificar en el sitio del "corralillo", recientemente adquirido para ese fin. Este equipo técnico concretaba los términos de la obra apuntando la construcción de una nueva escalera pero aprovechando las gradas de la anterior; el alzado de la pared que había de cerrar ambas salas por el oeste sobre el cimiento viejo saneado; y el labrado del testero septentrional en donde montar de nuevo la puerta principal. Planteamientos que en buena parte asumían las últimas propuestas de Ardemans, dando como resultado el crecimiento del proyecto inicial y su tasación en torno a los 132 mil reales de vellón. En cualquier caso el citado Pedro González abordaría un nuevo examen de los planes y presentaba en 16 de junio una circunstanciada memoria de la obra a realizar, con un valor previsto de 296.273 reales, donde aparecía sumamente definido el proyecto para levantar la obra interior del ayuntamiento con la condición primordial de que «se ha de continuar y ejecutar en la forma que corresponde a la fachada que está ejecutada y traça que le corresponda..." ${ }^{23}$. La declaración del arquitecto toledano evaluaba los gastos conforme a una minuciosa relación de instrucciones concretas en todos los aspectos técnicos de la edificación. Así, en lo referido a la albañilería, señalaba que la pared nueva habría de ser de dos anchos según la altura de sus salas (la baja levantaría seis metros y la alta ocho y medio, teniendo ambas una longitud de casi veintiocho) y su aparejo de pilares de ladrillo historiados con cajones de piedra de mampostería averdugados "como se demuestra en la planta del dicho Pedro González", reservando los huecos de ventana para su elección posterior y coronando el muro con una cornisa de ladrillo; se aseguraría la pared intermedia reforzándola con cuatro pilares y acrecentando su altura para enrasar con la nueva, algo más alta, «pues para la proporzión de la sala alta conviene que se execute la traça de dicho Dn. Theodoro Ardemanus», a quien

AMT, ibidem.

23 $\mathrm{AMT}$, ibidem. 
también se habría de seguir en el trazado de los suelos y encamonados de las salas. En el solar agregado se concebia edificar la caja de escalera, siguiendo el plano del testero norte y con alzado de albañilería, y de este modo ampliariase el espacio del zaguán, cuya fachada exterior se laboraría en piedra, acogiendo la portada, que, relabrada, se volvería "a sentar con sus vasas y capiteles... como lo demuestra la traça" y teniendo prevista la realización de un segundo cuerpo de cantería sobre la citada puerta "que venga atado con el edificio" renacentista ${ }^{24}$. González formulaba la conveniencia de hacer una nueva escalera, de tres tiros y sus cuatro rellanos, con gradas de nueve pies y medio de largo y pasamanos de forja labrada, sobre "cepa y pilar de sillería... con vasa y cornisa» de casi tres metros y medio de alto; mientras que la sobreescalera llevaría un cielo raso encamonado y cornisa de yesería. Contemplaba también la construcción de dos capillas con sendas sacristías para el servicio de ambas salas; solados, jaharrados y blanqueos, carpintería de puertas y ventanas y cerrajería completarían los trabajos de acabado.

Por tanto, estamos ya ante un proyecto decisivo, elaborado a partir de las propuestas esbozadas por los dos principales arquitectos, Ardemans y González, en el que pocas serán las modificaciones introducidas posteriormente en la línea de una simplificación y readaptación de las ideas de Ardemans, sin trastocar apenas la concepción arquitectónica del madrileño plasmada en sus dibujos y aceptando el peso decisorio del maestro toledano en el aspecto final del edificio. Lo cierto es que, en adelante, la obra se verá continuamente estudiada y reconsiderada a solicitud de los comisarios, cuyo celo les hace recurrir constantemente al parecer de los dos arquitectos, a medida que la fábrica vaya avanzando. En el caso de la escalera nueva, no parecía estar clara su colocación en el nuevo ámbito del zaguán; no obstante, en la memoria de la piedra berroqueña necesaria para su obra se dice que ya está delineada, es decir, que en 27 de julio de 1695 Ardemans tenia dada las trazas de la misma, con posterioridad al proyecto global (fig. 4) ${ }^{25}$. Aún en Toledo (en octubre de ese año) Ardemans emite, tras dos meses en la dirección de la obra, algunas objeciones al desarrollo de los trabajos en manos de los maestros albañiles y carpinteros ${ }^{26}$, avisando de los defectos en la ejecución de parte de la armadura de parhilera; rectificando la altura de la techumbre de la escalera, para su desahogo, «proporçión y hermosura»; proponiendo

AMT, ibidem. Hoy la traza no se ha conservado.

AMT, ibidem. Las trazas sí han llegado hasta nosotros.

AMT, ibidem. 


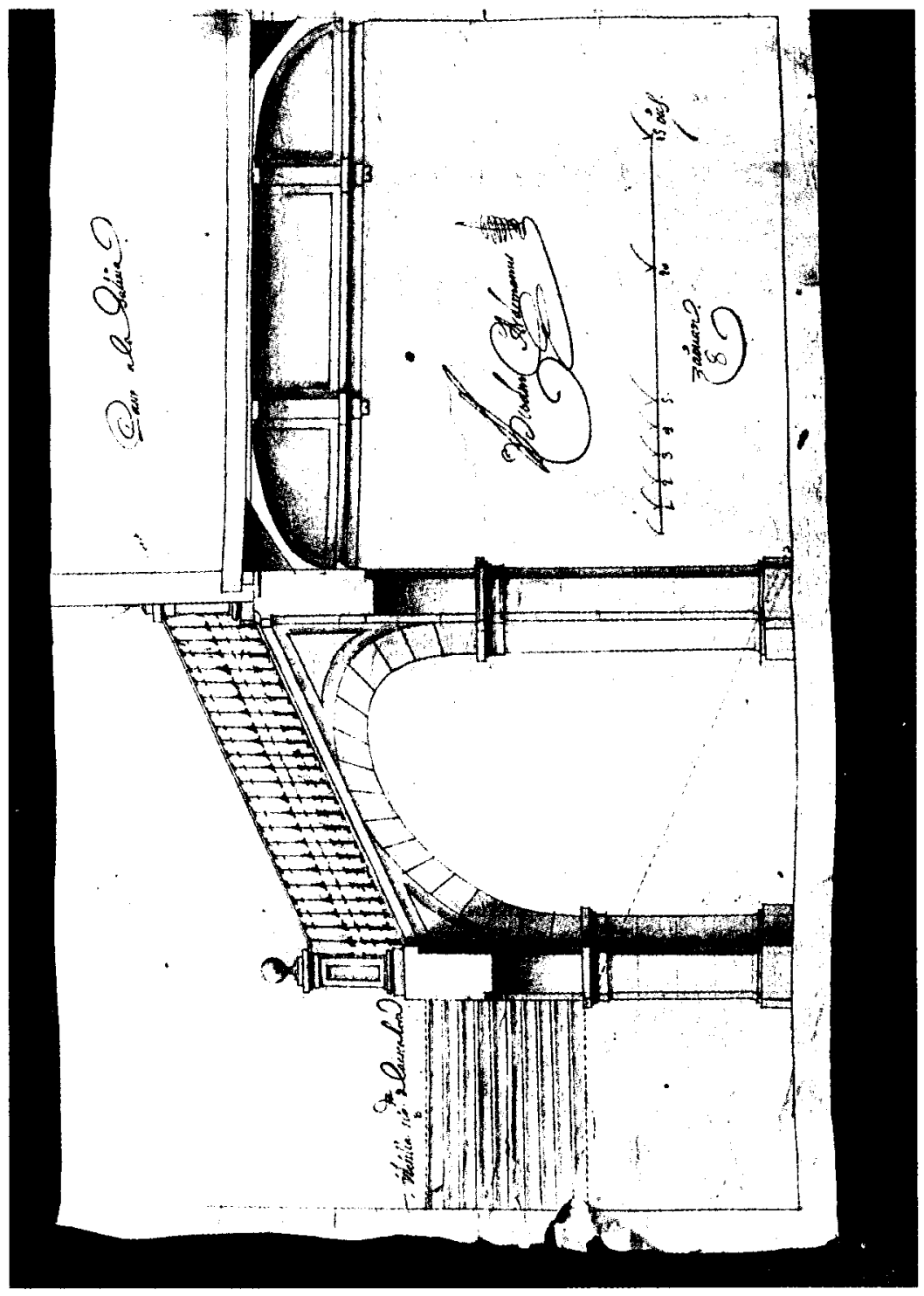

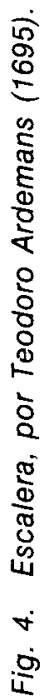


para el tercer tiro de escalera un cerramiento de pilastra a pilastra bajo el arco tranquil, solución conveniente que él dice haber observado en escaleras tanto toledanas como madrileñas. Este informe tuvo que ser expuesto y discutido en la comisión municipal, reunidos el propio Ardemans con Pedro González y los maestros de albañilería Juan Díaz y Matías Gutiérrez y los de carpintería, Juan Fernández y Gregorio Gómez. El 27 de octubre declararon que ya se estaba atirantando a mayor altura la armadura que cubría el salón y galería alta, que se levantaría la sobreescalera con un tabique en seis metros y que se macizaría el hueco de escalera referido; además, del esquilfe se dice que "se hará traça para el tiempo de su execución" "27. El mismo maestro mayor de la Santa Iglesia, en carta autógrafa firmada en Madrid, en 3 de noviembre, realiza las últimas consideraciones sobre la obra ${ }^{28}$. En concreto, para la fachada norte sugeria definitivamente subir "más que el nivel de la segunda cornisa", señalando la colocación de una amplia ventana sobre la portada principal; también volvía a iterar que «luego remitiré la traza del esquilfe de la escalera».

Mediado el citado mes, los trabajos se encontraban bastante avanzados por cuanto ya se habian colocado la cruz, bola y veleta en el tejado de las salas ${ }^{29}$. Se venía obrando en la escalera al mismo tiempo, continuándose la obra del zaguán hacia abril de 1696 , en que ya han sido levantados los tres arcos de separación sobre los que apoyarían las piezas superiores de capilla y sacristías ${ }^{30}$. En definitiva, tanto la obra interior de salas, portal y caja de escalera como el alzado de la fachada septentrional se podían considerar terminadas antes de finalizar el citado año, bajo el corregimiento de Don Martín Basurto Sepúlveda, quien se arrogaba el haber reedificado desde los cimientos ambas salas, oratorios y sacristías, engrandando la escalera principal y ia nueva fachada de cantería ${ }^{31}$.

Hasta aquí hemos reparado en los datos sobre lo concerniente a la edificación perentoria del bloque interior de las casas de ayuntamiento,

27 AMT, ibidem. . Traza no conservada.

28 AMT, Obras de ayuntamiento (1690-1799). Hoja suelta a continuación del primer cuaderno.

29 AMT, Obras de ayuntamiento (1690-1799). "Cuaderno de Cuentas de 1695 a 1700". Partida fechada en 16 de noviembre de 1695.

so AMT, Ibídem. En 26 de abril de 1696 se ponía una viga grande de Cuenca sobre los citados arcos.

31 AMT, Actas Capitulares, "Libro de 1696". Ayuntamientos de 13 y 19 de octubre de ese año. Cuando este corregidor tomó posesión del cargo el día 13, lo hacía en la sala alta, ya perfectamente acabada para la ocasión. De igual modo, se celebró el acto de bendición y colocación de la imagen de la Concepción en el oratorio de dicha sala un sábado, 20 de ese mismo mes y año. 
la que podríamos llamar primera etapa de la construcción. Los documentos no se agotan y, por supuesto, la obra del consistorio se prolonga con la realización de las dos torres laterales de su fachada principal, la segunda etapa de la construcción. Antes del 16 de julio de 1695 el regidor Don Fernando de Robles proponía al Capítulo municipal el solicitar al Consejo Real una prorrogación del arbitrio destinado para «seguir la fábrica de buena arquitectura y fortificazión y ser nezesario continuar con la fábrica de las torres" ${ }^{32}$. Y es cierto que en la conocida tasación de Pedro González, fechada entonces, se expresaba el coste que tendrían los dos chapiteles de madera en blanco más el empizarrado, emplomado y faldones que serían construidos "guardando la traça de Gregorio Gómez que tiene dada antes de ahora" y con la previa elevación del cuerpo de las torres en cinco pies (apenas metro y medio) sobre la línea de cornisa de la fachada principal ${ }^{33}$. Con estas condiciones hemos de reconocer la falta de un proyecto grandioso de torres y la persistencia de la idea simple de colocar tan sólo dos potentes chapiteles, como lo demuestra el que en 4 de junio de 1696 el maestro de albañilería del ayuntamiento Francisco de Huerta emitió un informe, acompañado de croquis, sobre cómo construir de forma sencilla las por él llamadas torres ${ }^{34}$, coincidiendo en proponer un banco cuadrado de obra, de tres pies de altura, adornado con cuatro bolas angulares, para soporte de un chapitel que, empezado en cuadro, terminase en ochavo ${ }^{35}$. Se trataba de una formulación recuperada por este alarife para dirimir la viabilidad del discutido proyecto firmado por Teodoro Ardemans, consistente en la planificación de torres ochavadas. En efecto, Ardemans redactaba en Toledo (8 de marzo de 1696) las condiciones bajo las que se construirían las torres de las casas consistoriales ${ }^{36}$, refrendadas luego por los señores comisarios de la obra para que se hiciera "todo conforme a la traça de Dn. Theodoro Ardemanus" ${ }^{37}$. La aceptación de este plan innovador era asumida por los mismos maestros y alarifes implicados en la construcción, P. González, F. de Huerta y

32 AMT, Obras del ayuntamiento (1690-1799). «Primer Cuaderno (1695-1697)".

${ }_{33}$ AMT, ibidem. Se sabe, por documento datable en 1681, que Gregorio Gómez había presentado traza para chapiteles cuadrados «en forma de ochavo matado el ángulo», con una altura de 52 pies hasta la bola, y por un precio de 44.000 reales, véase nota 35 .

${ }_{34}$ AMT, Obras de ayuntamiento (1690-1799). Hojas sueltas unidas al primer cuaderno. EI dibujo se ha conservado.

${ }^{35}$ AMT, Sección Obras. Caja: Obras del ayuntamiento (1575-1689). Documentos sueltos, fechados en 1681, donde se nos dice que Bartolomé Zumbigo y Francisco de Huerta dieron sendas trazas de chapiteles, no llegados a construir.

${ }_{36}$ AMT, Obras de ayuntamiento (1690-1799). "Segundo Cuaderno (1697-1702)». No está foliado y contiene documentos relativos a la obra de las torres.

${ }^{37}$ AMT, ibidem. La traza no se ha conservado. 


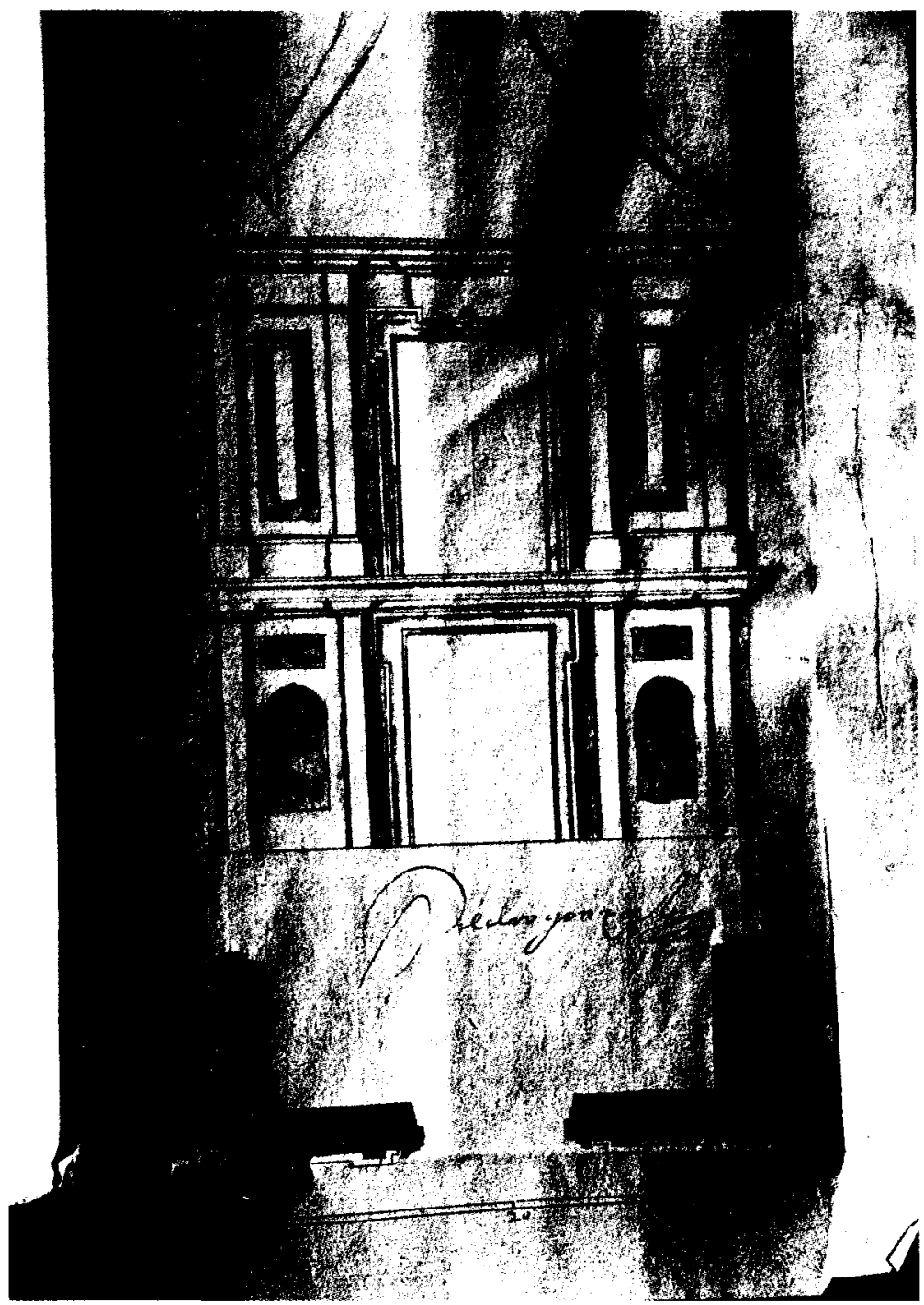

Fig. 5. Alzado y planta de torre, por P. González (1697).

M. Cabezas, quienes juntamente instruyen las bases para hacer la obra teniendo presente el problema técnico que conllevaba la superposición de un prisma octogonal de cantería con su chapitel encima de la planta cuadrada de lo levantado en 1618 , por otra parte, con grandes carencias 
de solidez ${ }^{38}$. Ellos entienden que para cargar el nuevo cuerpo se precisaba fortalecer la base preexistente, recreciéndola sobre los dinteles de las ventanas, previniendo al mismo tiempo los correspondientes arcos escarzanos de descarga y macizando los ángulos con arquillos de piedra apuntados, apoyados en canes. De este modo, sobre una sección cuadrada de 6,5 metros de lado se levantaría un ochavo con 4,3 metros de lado mediante un sistema de trompas, de cierto aspecto gotizante, con el fin de regular y equilibrar la tectónica de edificio y torres.

De hecho, la construcción de una de las torres estaba ya concertada ${ }^{39}$ cuando surgió la oposición abierta al plan de Ardemans en mayo de 1697. De nuevo, la comisión de obras exigía la revisión del proyecto de torres a los maestros Eugenio Díaz, cantero que hace la obra, y los conocidos Juan Muñoz de Villegas, Huerta, Cabezas, y el aparejador de la Catedral, los cuales estudiarán si sobre la fábrica antigua podrá cargar la planta delineada por el arquitecto madrileño ${ }^{40}$. La división de pareceres se polariza, mostrándose contrarios a la edificación los dos primeros mientras que los demás convienen en aceptar las trazas siempre que se fortifique la base cuadrada de la torre. No concluye el mes de mayo sin que los mismos maestros verifiquen su juicio en nueva comparecencia ante el Capítulo, al tiempo que Ardemans intentaba quedarse con la insinuada obra para realizar así su proyecto, ante el cual se mostraban tantas reticencias e inseguridades. Un continuo examen técnico del discutido proyecto llevará a la junta pericial a solicitar, en 6 de julio, la modificación de los diseños y el cambio de figura de las torres y, en consecuencia, a determinar como alternativa consensuada la planta cuadrada y figura cúbica de las mismas, siendo Pedro González quien firma las nuevas trazas (fig. 5), y cuyo dibujo e informe favorable se aprobó decididamente por los capitulares ${ }^{41}$.

En 23 de junio de 1700 se certificaría la conclusión de la primera torre y chapitel, la meridional, por Juan Gómez Castellanos y la segunda, empezada a mediados de 1702 , se terminaba en el verano del siguiente año, según lo declaran Pedro González y los alarifes ${ }^{42}$.

\footnotetext{
${ }^{36}$ AMT, Obras del ayuntamiento (1690-1799). Hoja suelta unida al segundo cuaderno. Fechada en Toledo a 8 de junio de 1697.

39 AMT, Obras del ayuntamiento (1690-1799). "Segundo Cuaderno (1697-1702)".

40 AMT, ibidem

${ }^{41}$ AMT, ibidem.

42 AMT, Actas Capitulares. “Libro del año 1700». Ayuntamiento de 25 de mayo. Y Obras de Ayuntamiento (1690-1799). "Tercer Cuaderno 1703". Con documentación sobre la obra de la segunda torre en 1703. No está foliado.
} 


\section{TEODORO ARDEMANS Y LOS MAESTROS TOLEDANOS}

Se ha visto que hasta la aparición de Teodoro Ardemans, estante en Toledo en abril de 1695, el Ayuntamiento venía recurriendo a sus alarifes, competentes maestros de obras de la propia ciudad, para evaluar y procurar los reparos del edificio consistorial; solicitando igualmente al por entonces maestro mayor de obras municipal, Juan Muñoz de Villegas, un informe pericial sobre el estado ruinoso de la pared maestra de las salas. No obstante, la comisión de obras se dirigirá también al maestro mayor de obras de los Reales Alcázares de Toledo, el «maestro arquitecto» Pedro González, para disponer los oportunos apuntalados en 1694.

A partir de aquí, estos y otros maestros toledanos entrarán en relación con la obra de las casas de ayuntamiento desde los condicionamientos profesionales vigentes en el contexto laboral de finales del siglo XVII al que el Toledo de estos años no es extraño. En el caso de la obra aquí referida, el comitente indiscutible es la corporación municipal, que encarga excepcionalmente la edificación y construcción de parte de su sede institucional, delegando en una comisión de cuatro capitulares eficientes la gestión de toda la obra.

Cuando la Ciudad Imperial se dirige a S.M. Carlos II en 4 de marzo de 1695, para solicitar providencia que asegurase los medios económicos para sostener la obra ya aprobada, lo hace en estos términos: «... y se teme mayor ruina no sólo en las dichas dos salas y artesones della sino es en el lienço y fachada prinzipal que hermosea dichas casas de ayuntamiento, fábrica de las más singulares que tienen estos Reinos" ${ }^{43}$. Resulta, pues, que en torno al cometido y obra de las citadas casas se puede constatar la categoría de los maestros que intervienen de una $u$ otra forma en proyectos y ejecución, atendiendo a su cualificación profesional y su lugar en el contexto gremial de la ciudad. El bloque interior de ayuntamiento se habia de reedificar y para ello se busca a un arquitecto con título de maestro mayor que reconozca, valore y plantee la obra. Es el caso, primero, de Pedro González, reconocido «Maestro de Arquitectura y mayor de los Reales Alcázares de esta ciudad y aparejador de obras de la Sta. Yglesia de ella y vecino de esta ciudad"; y, en segundo lugar, de D. Teodoro Ardemans, "Architecto y maestro mayor de obras" de la Catedral y afincado en Madrid. Ambos, en 1695, realizaban las trazas y redactaban las condiciones y memoria de materiales, como es sabido. Representaban, pues, el escalafón más alto dentro de su profesión, con

\footnotetext{
43 AMT, Actas Capitulares. «Libro del año de 1695". Ayuntamiento de 14 de abril.
} 
titulación, eso sí, no vinculada ni conferida por la institución ciudadana sino actuando como arquitectos cuyo conocimiento se requiere por cuestión de prestigio o experiencia probada. Si la labor especulativa corresponde a los arquitectos mencionados que han estudiado y diseñado la obra, para los trabajos efectivos se eligen a los maestros de obras que ejercen en la ciudad, verdaderos artífices prácticos en construir, quienes dirigen a su vez a un equipo anónimo y numeroso de oficiales y peones. Mediante una obligación contractual, la primera fase de la construcción corrió a cargo de los maestros Juan Díaz Aldeano, M. Gutiérrez y A. Pérez, todos ellos toledanos, implicados en las labores de albañilería. Para los trabajos de corte, tallado y montaje de los elementos de madera son Gregorio Gómez y Juan Fernández los maestros de carpintería, este último "por cuya quenta ha corrido lo que se ha ejecutado en dicha obra" (de la armadura de las salas) y aquél, virtual trazador de chapiteles no realizados ${ }^{44}$. Por otra parte, la obra de piedra berroqueña se contrataba con maestro específico del arte, Eugenio Díaz «a cuio cargo ha estado todo lo que se ha hecho de cantería, toda la piedra que procedió de las gradas de la escalera antigua para efecto de haçer solados a las entradas de la escrivanía maior y contaduría $=$ zintas y buçones del portal $=$ y tránsitos de la escalera y cinta de la sala baxa $=$ y asimismo de diferentes pieças de mármol negro que ha dado labrado y sentado para dicha sala" ${ }^{45}$. También a este maestro cantero se le volverá a contratar en la segunda fase de la obra para labrar los cuerpos de las dos torres, que realizó bajo obligación y encargo que Juan Gómez Castellanos, maestro de carpintería, firmó sobre la fabricación de torres y chapiteles ${ }^{46}$.

Por su parte, el Ayuntamiento regulaba mediante antiguas ordenanzas la política urbanística, empleando para ello a distintos maestros aprobados en sus respectivos gremios, pertenecientes a la albañilería, carpintería y cantería ${ }^{47}$. Existe, pues, una plantilla jerarquizada de profesionales al servicio de la ciudad que comprende oficios diferenciados. Asi, aparecen los "veedores", una de cuyas obligaciones es "no haçer visita sin los cavalleros sobreveedores" ${ }^{48}$, es decir, acompañar al edil supervisor en toda inspección; otrosí, su facultad como examinadores. La duración anual de su desempeño y la subordinación a un cargo municipal son datos que

44 AMT, Obras del ayuntamiento (1690-1799), "Primer Cuaderno (1695-1697)».

45 AMT, Obras del ayuntamiento (1690-1799). Hoja suelta unida al primer cuaderno. Es la declaración de Miguel Cabezas fechada en Toledo a 10 de mayo de 1697

46 AMT, Obras del ayuntamiento (1690-1799), "Segundo Cuaderno (1697-1702)".

47 SuÁrez Quevedo, D., Arquitectura barroca en Toledo: siglo xvil. Toledo, Obra Cultural de la Caja de Toledo, 1990, pág. 67.

«A AMT, Actas Capitulares. "Libro del año 1696". Ayuntamiento de 23 de mayo. 
nos hacen pensar en la poca relevancia de este empleo de clara representación gremial. Un trabajo satisfactorio puede motivar que el Ayuntamiento otorgue título de "veedor perpetuo" de forma honorífica y vitalicia como sucedió con los anteriormente citados Juan Díaz y Juan Fernández por su aplicación práctica y teórica a la obra del consistorio ${ }^{49}$. Desde veedor o maestro de obras cualificado se podía acceder al puesto de «alarife», persona encargada por el municipio en lo concerniente a policía urbana, como lo expresan las ordenanzas municipales desde el año de $1562{ }^{50}$. El alarife reconoce, tasa, mide y estima, cuantas veces se le ordene, el estado de solares, ruinas, casas, calles, canalizaciones, muros y evalúa reformas, ampliaciones, derribos y todo lo que afecta a obras públicas y particulares, con el fin de contribuir al perfecto ordenamiento urbano de Toledo. Sus informes y dictámenes sirven para prescribir los permisos oportunos de obras y están avalados por su considerable cualificación técnica, a la cual se somete la autoridad municipal. A veces, su cometido puede equipararse al de aparejador, pues en cualquier momento es capaz de dar trazas y de hecho, en su actividad extramunicipal, suele proyectar obras diversas, civiles o religiosas. La consecución del cargo de alarife suponía para un maestro albañil, carpintero o cantero, alcanzar un grado superior en la carrera profesional y el consiguiente reconocimiento bajo el patrocinio de la Ciudad ${ }^{51}$, lo que sin duda facilitaría su promoción a una maestría mayor o le capacitaría como arquitecto con aptitud de teórico trazador. El empleo de alarife se extinguía con la muerte del poseedor y la vacante se cubría por oposición ${ }^{52}$. En estos momentos, alarifes implicados en la obra del ayuntamiento son Francisco González, en albañilería, Miguel Cabezas y Francisco de Huerta, en cantería e Ignacio Arias, en carpintería. Por tanto, cuatro alarifes, que quedaban adscritos a sendos cuarteles o distritos urbanos como zonas de sus repectivas competencias.

La «maestría mayor de la ciudad» era el máximo empleo dispensado por el ayuntamiento, en calidad de vitalicio. En estos años lo disfrutaba en propiedad el octogenario Juan Muñoz de Villegas, activo en labores relacionadas con la dirección de la obra de cantería y tracista de los arcos

49 AMT, ibidem. Ayuntamiento de 8 de febrero de 1697.

50 SuÁrez Quevedo, D., Op. cit.,, Arquitectura barroca..., págs. 67 y 68 . Véase también Martín Gamero, A., Ordenanzas para el buen Régimen y Gobierno de la Muy Noble Muy Leal é Imperial Ciudad de Toledo. Toledo 1858.

51 Suáaz Quevedo, D. ibidem, pág. 71.

52 AMT, Actas Capitulares. “Libro del año 1696». Ayuntamiento de 6 de febrero de 1697. Entonces, el examen de alarife de carpintería lo hace Pedro González con los candidatos "habiéndoles hecho diferentes preguntas tocantes a dicho ofiçio y a leer y escrivir y contar...". 
de la escalera a finales de 1695 , poco antes de su muerte ${ }^{53}$. Debemos de pensar en funciones de eventual aparejador en aspectos parciales de la construcción. La denominación como “Arquitecto Maestro Mayor» nos plantea dudas acerca de la verdadera cualificación técnica de los maestros mayores municipales. $Y$, en efecto, que un maestro en arquitectura como José Machín, ensamblador y retablista toledano, ocupara en diciembre de 1695 la vacante dejada por Muñoz de Villegas nos ratifica en la ambigüedad de este cargo sumo que se otorga a un artífice cuya manifiesta formación no es la propiamente constructiva o edilicia que sugiere tal título y su actividad ${ }^{54}$. Se puede concluir afirmando que el llamado maestro de arquitectura es en el tránsito de un siglo a otro un maestro enseñado y ejercitante, ante todo, en el arte de la talla y ensamblaje de retablos, hábil en el dibujo para idear modelos arquitectónicos, pero supuestamente inexperto y sin conocimientos prácticos en levantar obras de fábrica; situación, por otra parte, tan habitual en el Toledo de los siglos XVII y $x \mathrm{VVIII}^{55}$.

Sí quisiéramos, antes que nada, recordar que otra institución, la Obra y Fábrica de la Iglesia Catedral de Toledo, disponía del servicio de maestros de obras, empleados en distintos cometidos y con su titulación correspondiente. En primer lugar, destaca el maestro mayor de la misma, a la sazón Teodoro Ardemans; en un segundo lugar, el aparejador, el arquitecto local Pedro González; y, en tercer lugar, el sobreestante, que lo era Francisco de Huerta, el también alarife municipal. Todos ellos, vinculados a la Dignidad Arzobispal pero libres en el ejercicio de su profesión ante la solicitud de cualquier comitente.

En todo caso, esta jerarquización de títulos y funciones, a veces mal definidas, parece reproducirse en el sistema de organización de la obra municipal, en la que es el Ayuntamiento el que realmente otorga la primacía a los planes discurridos por Ardemans hasta la desestimación de su proyecto de torres ochavadas. En tanto que González, el arquitecto de confianza del municipio y subordinado a la dirección del madrileño, acabará imponiendo sus criterios y su alternativa en la edificación definitiva de las torres; de modo que de colaborador en funciones de asesor y aparejador, en la obra del bloque interior, se alza en arquitecto indiscutible a la hora de trazar las torres cuadradas, siempre con el consenso de los demás maestros locales. Pedro González se nos presenta como el maestro mayor de obras más reputado en Toledo después de la desaparición

\footnotetext{
53 AMT, Obras de ayuntamiento (1690-1799). "Cuaderno de Cuentas de 1690 a 1700". Partida de 24 de diciembre de 1695.

54 AMT, Actas Capitulares. "Libro del año 1697". Ayuntamiento de 20 de diciembre.

55 SuÁrez QueVedo, D., Op. cit., Arquitectura barroca..., págs. 65 y ss.
} 
del que fuera Maestro Mayor de la Santa Iglesia y Aparejador de los Reales Alcázares, D. Bartolomé Zumbigo ( $\dagger 1682$ ), y hasta su muerte en $1707^{56}$. No es equivocado pensar en su formación toledana puesto que se constata su actividad en torno a 1665, como sobreestante de las obras del Ochavo catedralicio, y trabajando como aparejador de la Catedral a las órdenes de Zumbigo, Donoso y Ardemans, maestros mayores bajo el arzobispado del cardenal Portocarrero (1678-1709); llegando a ser desde 1685 el Maestro Mayor de Obras del Alcázar toledano ${ }^{57}$, prevaleciendo su actuación como trazador de varias iglesias dentro de la diócesis. A Pedro González corresponde realmente el primer proyecto de edificación de las salas del ayuntamiento de Toledo, elaborado en las primeras semanas de enero de 1695, pues a él acude el comisariado de la obra "por la satisfacción que de él se tiene y ha hecho tanteo de la costa que pareze ha de tener y de las condiciones con que se ha de executar la dicha obra y planta para ellaw ${ }^{58}$.

La participación de Teodoro Ardemans en la obra del consistorio de Toledo ha sido conocida pero nunca corroborada con precisión, lo que ha inducido a errores de atribución al arquitecto madrileño de tal o cual parte de lo construido entre 1695 y 1703 . Por ello, se hace oportuno exponer las vicisitudes que rodean la actuación del madrileño y el alcance real de su trabajo, dilucidando a la vez sus relaciones con el medio profesional local y constatando el peso distintivo de la maestría toledana a la hora de valorar, replantear y ejecutar la obra desde las propuestas del reputado arquitecto cortesano. Teodoro Ardemanus, que así firma en estos años en los documentos estudiados, había accedido al empleo de Maestro Mayor de la Santa Iglesia Catedral de Toledo en 21 de marzo de $1691^{59}$. Desde 1690 hasta 1692 desempeñó los cargos de Maestro arquitecto y alarife de Madrid, interviniendo entonces en la obra del ayuntamiento de esa capital trazando portadas, parte del patio y las torres; siendo desde 1692 el Maestro Mayor de obras de la Villa ${ }^{60}$. En Toledo, fuera de los encargos para la catedral, al parecer insignificantes o no bien conocidos,

\footnotetext{
56 Archivo Histórico Provincial de Toledo (AHPT), Protocolo 485, año 1707, folio 115. En 1695 Pedro González tenía 53 años confesados, mientras que Teodoro Ardemans contaba con diecinueve menos.

57 Rodríguez Martín, José M., El arquitecto toledano Bartolomé Sombigo y Salcedo (16201682). Toledo, Exmo. Ayto. de Toledo, 1988, pág. 73. También, SuÁrez Quevedo, D., Op. cit., Arquitectura barroca..., pág. 14

5B AMT, Obras del ayuntamiento (1690-1799). «Primer Cuaderno (1695-1697)».

59 Blasco Esouivias, Beatriz, Teodoro Ardemans y su entorno en el cambio de siglo (1661. 1726). Tesis doctoral, Universidad Complutense de Madrid, 1991, t. I, pág. 19. Esta obra estudia exclusivamente el entorno madrileño del arquitecto.

60 Blasco Esouivias, B., ibidem, t. 1, pág. 151.
} 


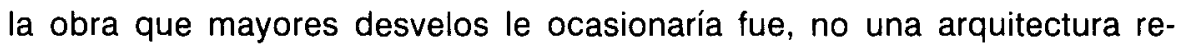

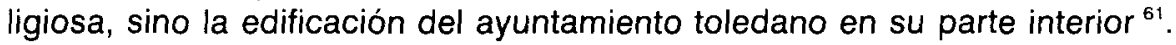

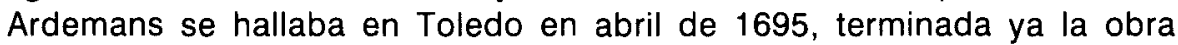

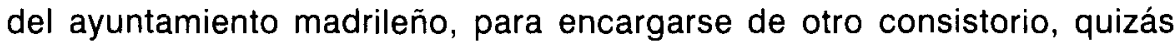

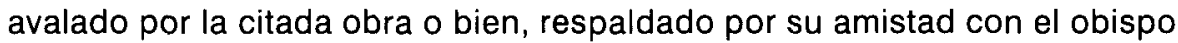

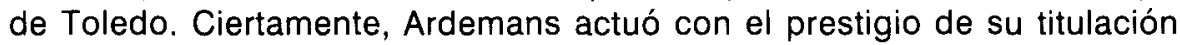

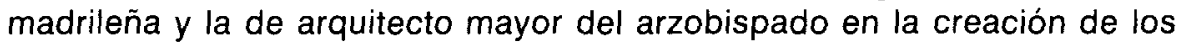

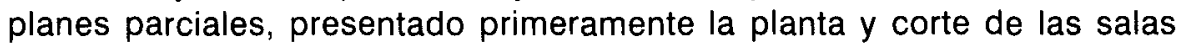

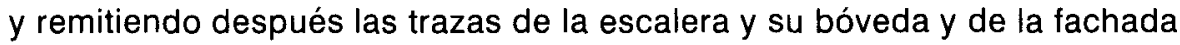

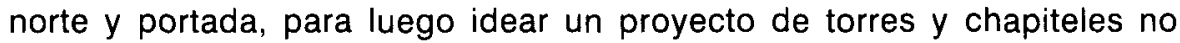

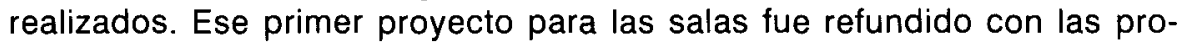

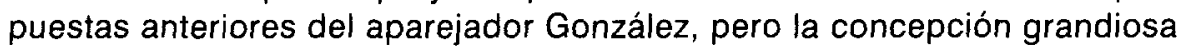

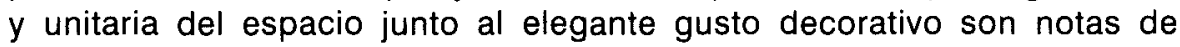

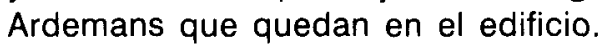

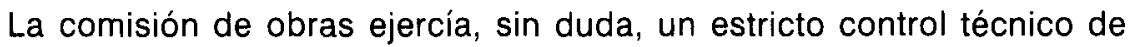

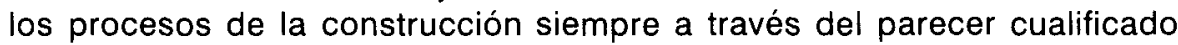

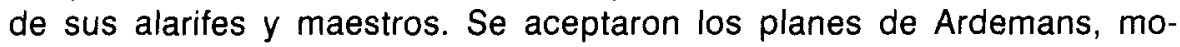

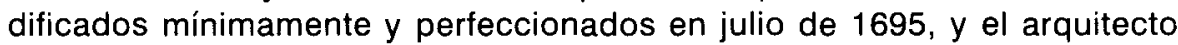

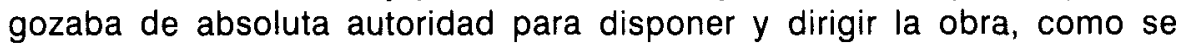

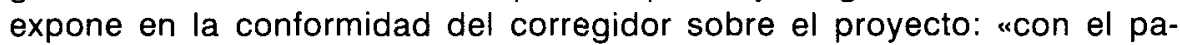

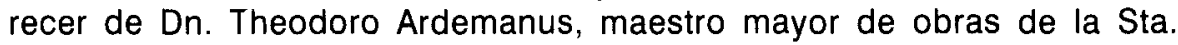

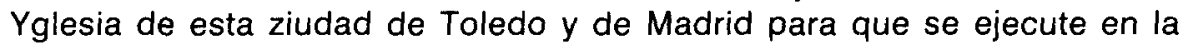

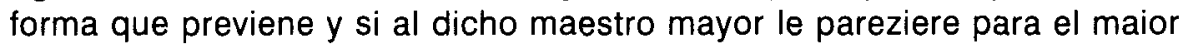

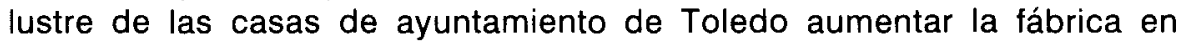

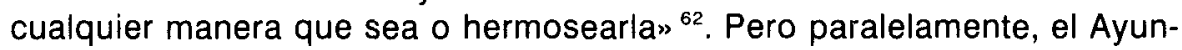

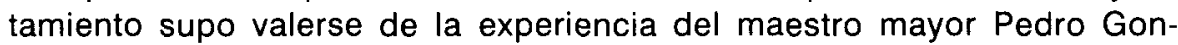

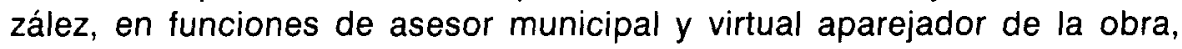

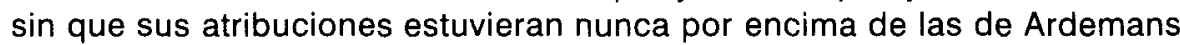

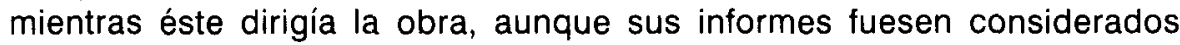

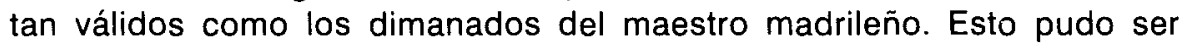

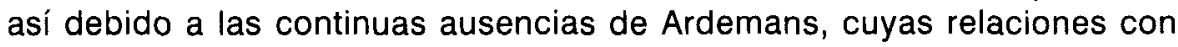

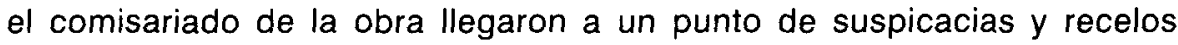

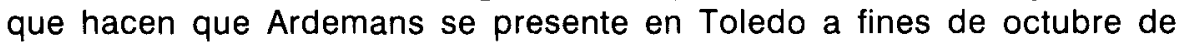

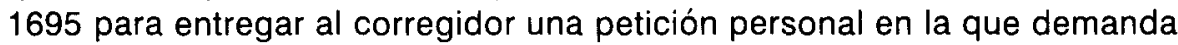

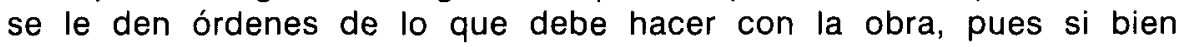

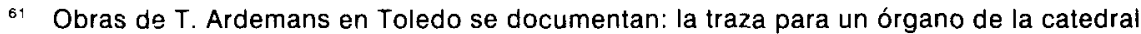

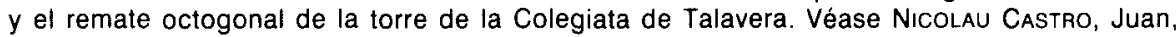

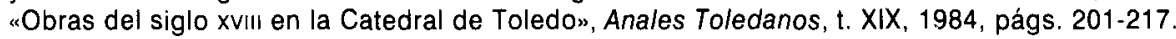

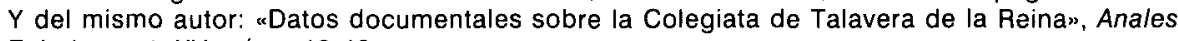

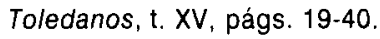

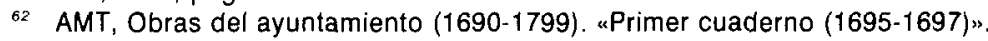


reconoce honrosamente el haber asistido con su dirección y con arreglo a su planta y condiciones, sin embargo, "si alguna dificultad se ofrecía se me pedía parecer, para proseguir en su execución (lo qual he echado de menos muchos días y no sólo yo sino es también la obra); parece se observan ásperamente mis dictámenes y advertencias pues lo que al principio se admitía por obsequio hoy se admite por pesar, y cierto, señor, sentiré mucho que no corresponda la execución de la obra al buen deseo que he tenido $y$ tengo de servir a V.S." ${ }^{63}$. Ardemans, en esas mismas fechas, daría de nuevo un informe sobre el estado de la citada obra, reiterando su desconfianza al manifestar que "desde el día veynte y siete de agosto de este año de noventa y çinco ha proseguido la obra de las casas de ayuntamiento de esta çiudad sin habérseme pedido parezer en el proseguimiento de su ejecución, y habiendo venido a reconozer el estado y ejecuçión de dicha obra he hallado haber corrompido mi disposición en las alturas...», por lo que no omite algunas rectificaciones, las cuales serán revisadas y aplicadas por la junta de maestros encargados de la obra ${ }^{64}$. El arquitecto de Madrid se ocuparía en adelante de realizar personalmente las memorias de la piedra berroqueña que se había de labrar para la escalera, incluso se permite hacer el rasguño de alguna montea ${ }^{65}$; labor en que parece ayudar ocasionalmente el maestro mayor de la ciudad, Juan Muñoz, firmando la relación de piedras para los machones de los tres arcos de la misma escalera ${ }^{66}$. Desde Madrid y en 3 de noviembre de 1695, Ardemans envió al regidor y comisario toledano D. Fernando de Robles una cordial y afable carta en la que indicaba que se había de subir la fachada norte sobre el nivel de la segunda cornisa, haciendo una ventana encima de la portada principal, y que prontamente mandaría el dibujo del techo de la sobreescalera ${ }^{67}$; ante lo cual nos cabe pensar en una normalización de las relaciones contraídas entre el Ayuntamiento toledano y el arquitecto, a quien competía la dirección y planteamiento de las partes de la edificación. Realmente, en reconocimiento de la dedicación de Teodoro Ardemans, el Ayuntamiento acordaba en 22 de enero de 1696 se le librarán 1.500 reales upor la ocupazión y travaxo que tubo en las disposiziones y trazas que dio para la obra” ${ }^{68}$.

Si hasta aquí hemos considerado la construcción del bloque interior y fachada norte de las casas de ayuntamiento de la que Teodoro Ardemans

63 AMT, ibidem.

AMT, ibidem.

AMT, ibidem.

AMT, ibidem.

AMT, Obras del ayuntamiento (1690-1799). Hoja suelta unida al primer cuaderno. Véase nota 28.

68 AMT, Obras del ayuntamiento (1690-1799). "Cuaderno de Cuentas de 1695 a 1700". 
parece induscutiblemente el autor del proyecto arquitectónico, no así se puede decir de la obra de las torres y chapiteles, pues, como se ha de ver ahora detenidamente, su plan encontró resistencias para ser realizado. Ocupado aún en la terminación de las salas y escalera, firma en Toledo a 8 de marzo de 1696 las dieciocho cláusulas para hacer dos torres con sendos chapiteles, que acompañaba de trazas no conservadas hoy; donde señalaba principalmente "que la forma de dichas torres ha de ser ochavada disimulando con los lados de su figura la yrregularidad del sitio", apilastradas en sus ángulos y asentadas mediante cuatro arquillos de refuerzo en los rincones del cuadrado del cuerpo que hace de base, con altos chapiteles empizarrados y emplomados ${ }^{69}$. Este segundo proyecto para la obra del ayuntamiento tuvo el beneplácito de la corporación municipal y el reconocimiento favorable de la junta de maestros, quienes de inmediato redactan las instrucciones para su correcta ejecución. Formalizada la escritura de obligación ${ }^{70}$ y comenzada la labra de la piedra por el maestro cantero Eugenio Díaz, es éste el que presentaba su oposición firme a levantar las torres de cuerpo ochavado por razones de índole práctica que han de propiciar la duda sobre la viabilidad del plan de Ardemans. Sabemos de la revisión continuada efectuada por la comisión de obras a través de la junta pericial lo que ocasiona una interrupción de la nueva empresa y un enfriamiento de las pretensiones de Ardemans. Ante este contratiempo, el arquitecto alega argumentos de interés profesional e insta a la autoridad de la ciudad a que se le traspase la obra de las torres «pues para executar por mí mesmo dichas torres no se me ofrece la más mínima dificultad, antes, sí se excederá en ellas pues quien executa la obra que desde su prinçipio cría la mira con más cariño que el que executa otras traças que no sabe ni entiende" ${ }^{71}$, desautorizando así a un sector de la maestría de formación gremial. Es ésta una defensa razonable de la condición del arquitecto creador, que concibe la obra y la estima teóricamente pero mostrando a la vez la capacidad práctica para materializar esa idea asumible en un edificio coherente con ella. Ardemans insistió en su propósito de llevar adelante el proyecto previsto contando con el apoyo de Pedro González, Francisco de Huerta y Miguel Cabezas, pero apelando de nuevo al corregidor toledano, con el ofrecimiento de una rebaja en el precio contratado, para poder quedarse con la obra y darla acabada con toda perfección a vista de peritos en el arte ${ }^{72}$. El hecho

\footnotetext{
AMT, Obras del ayuntamiento (1690-1799). "Segundo Cuaderno (1697-1702)".

AMT, ibidem.

AMT, ibidem.

AMT, ibidem.
} 
es que, transcurridos los meses y reunidas las comisiones consultivas, Ardemans perdía definitivamente la esperanza de una resolución benévola a su plan ante el nuevo planteamiento formulado en 6 de julio de 1697, que fue aprobado unánimemente por comisarios y maestros para modificar la estructura de las torres, cuyo diseño forma y firma Pedro González ${ }^{73}$.

Es entonces cuando, sin duda alguna, terminaba la participación de Teodoro Ardemans en las empresas edilicias del ayuntamiento de Toledo con este plan malogrado de torres. Por lo que respecta a la obra de los chapiteles, siempre considerados como el elemento más madrileño que corona la fachada del consistorio, y tenidos como obra personalísima de Ardemans, la documentación aquí aireada no puede ser más concluyente en desmentir esa autoría. La elección de torres cuadradas hubo de condicionar el nuevo trazado de chapiteles, pero sin que los expedientes de la obra nos aporten el nombre explícito del tracista, aunque no dudamos en atribuirlos indeterminadamente a alguno de los maestros toledanos, bien Gregorio Gómez o bien Francisco de Huerta, quienes en principio, antes de proyectarse incluso los cuerpos de torres nuevas, plantearon chapiteles para colocar directamente sobre el cuadrado de la fábrica renacentista a modo de simples agujas, y cuya forma se hubo de retomar ahora que las torres volverían a ser cuadradas. Si es cierto que estas trazas toledanas se postergaron al promoverse el plan de torres ochavadas en virtud de que "para la fábrica de los chapiteles de dichas casas de orden de la comisión está hecha traça por Dn. Theodoro Ardemanus que es la que la comisión tiene elejida de todas las traças que antiguamente estaban hechas y al presente se han hecho" ${ }^{74}$, no resulta extraño que posteriormente se reutilizaran. En definitiva, el chapitel sobre base cuadrada que se realizó para cubrir las torres es el mismo que aparece esbozado en el dibujo de torres de González y que Francisco de Huerta ofrece en planta ${ }^{75}$, o que Gregorio Gómez describe como ochavado ${ }^{76}$, con lo que vemos que la idea de chapitel de base cuadrada y con alzado terminado en ochavo estaba ya perfilada entre los maestros de obras y maestros carpinteros toledanos que componían la junta pericial municipal y ni siquiera es posible reconocer una asimilación directa de ideas de Ardemans aunque no se descarte la influencia generalizada del barroco madrileño en la tipología de las estructuras toledanas.

73 AMT, ibidem.

74 AMT, ibidem.

75 AMT, Obras del ayuntamiento (1690-1799). Hojas sueltas unidas al segundo cuaderno. El informe está fechado en 4 de junio de 1697.

76 Véase nota 33. 


\section{LA ARQUITECTURA BARROCA DEL AYUNTAMIENTO DE TOLEDO}

Si nos acercamos a la fachada septentrional, que cierra tras de sí el amplio zaguán y la escalera, se nos ofrece barroca por la fecha de su construcción pero realmente, como prolongación de la obra renacentista preexistente, resulta un compromiso de Ardemans con la ordenación estructural y compositiva dada, en la que insertó sin reparos la reutilizada portada principal, también del siglo xVI. Este pie forzado hace que este testero de cantería se integre sin disonancia aparente, conformando un plano en el que era preciso situar la portada con respecto a la nueva disposición interior del portal, y de este modo, redistribuir las líneas de articulación vertical acordadas con la fábrica precedente, usando macizos apilastrados y vanos adintelados. En su conjunto, la parte nueva de cantería no resulta simétrica pues el eje vertical de la portada y vanos superpuestos queda desplazado y colateral al eje ascendente de la torre lateral (fig. 6). Desde luego, Ardemans se vio comprometido a mantener una solución conservadora e incluso desistió de crear una portada de diseño barroco para adoptar una más clasicista, aunque de buenos efectos plásticos.

El zaguán, abierto tras el medio punto de acceso, está concebido como un espacio de dimensiones rectangulares y dividido en dos ámbitos y dos alturas: el portal abovedado y la caja de escalera, de considerable alzado (fig. 7). El primero queda cubierto en sus tres tramos transversales por sendas bóvedas de arista, la central algo más ancha. Una triple arcada, cuyos arcos (el central, rebajado y de medio punto los laterales) apoyan directamente en el capitel toscano de los dos pilares centrales y pilastras, cajeados sus netos y adornados con guardamalleta. La estructura espacial de este ámbito resalta por la sobriedad de su articulación en la que, sobre el enjaharrado de los muros, destaca el gris de la piedra (fig. 8).

Tras la arcada y en el sentido perpendicular al eje direccional del portal se desarrolla la escalera, que preside la espaciada entrada, en tres tramos rectos y dos rellanos. Iluminada por ventanal abierto en el muro norte y dos altos vanos bajo el techo, orientados al oeste, la escalera se acoge dentro de amplísima caja cubierta por bóveda encamonada. En ésta, un esquilfe se adorna a base de fajas y lunetos, y bajo la cornisa, placas recortadas, que se doblan en los ángulos, constituyen el motivo decorativo característico empleado por Ardemans; el cielo raso lleva pintura alegórica de la época, enmarcada por grueso baquetón moldurado.

El arquitecto madrileño consideró oportunamente la reforma del ingreso principal del ayuntamiento, ampliando considerablemente el espacio de entrada con el fin de organizar el emplazamiento de la escalera, ele- 



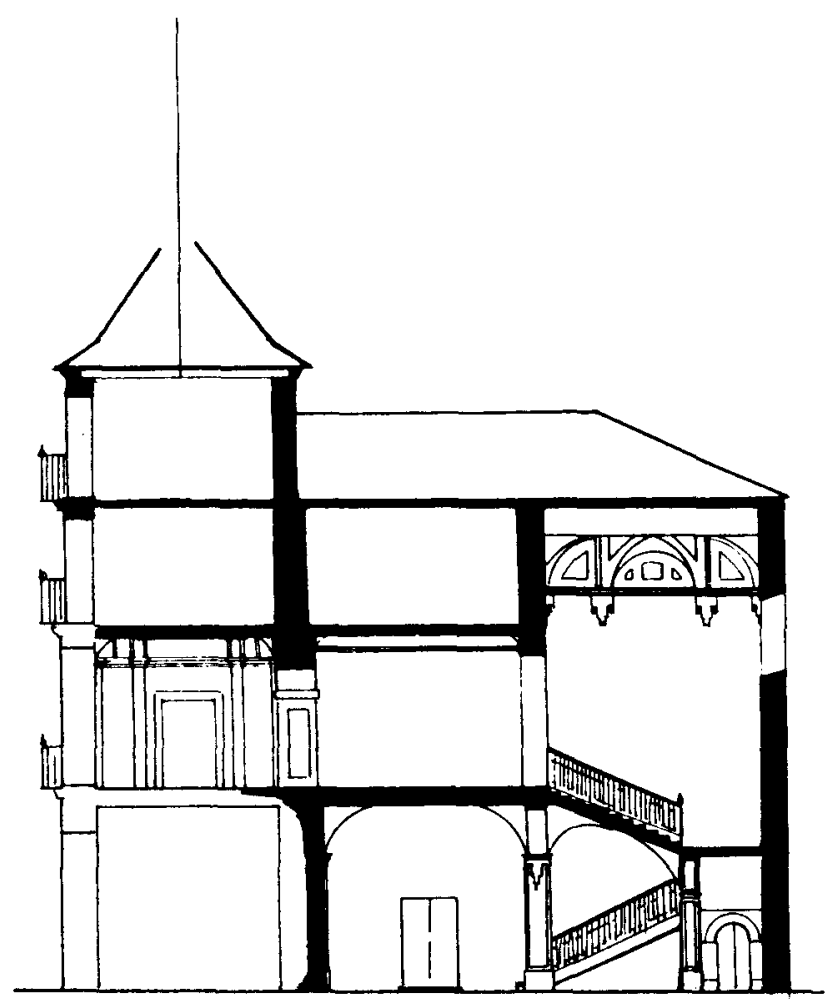

Fig. 7. Corte mostrando la escalera y partes construidas en 1696.

bóvedas del mismo zaguán (figs. 9 y 10). Mayor interés ofrece el espacio interior de ambas salas, en donde se hacen patentes las intenciones decorativas y el sentido proporcional del espacio impuesto por Ardemans, evidenciándose así la importancia de esta salas capitulares dentro de la vida y actividades municipales. En ellas, a través del recurso tradicional del techo encamonado, el arquitecto supo hacer uso de los efectos plásticos de clara filiación madrileña. Si bien el empleo comedido y regularizado de los motivos - por otra parte, nada exagerados--, geométricos y abstractos, a base, sobre todo, de placas recortadas, marcos con orejetas, fajas y modillones pareados, no resta plasticidad alguna, todo este molduraje pudo ser calificado de achurrigueresco en sus recargados adornos de yeso blanco" ${ }^{77}$ (figs. 11 y 12). La sala de arriba presenta en sumo

7 Parro, S.R., Op. cit., t. II, pág. 535. 



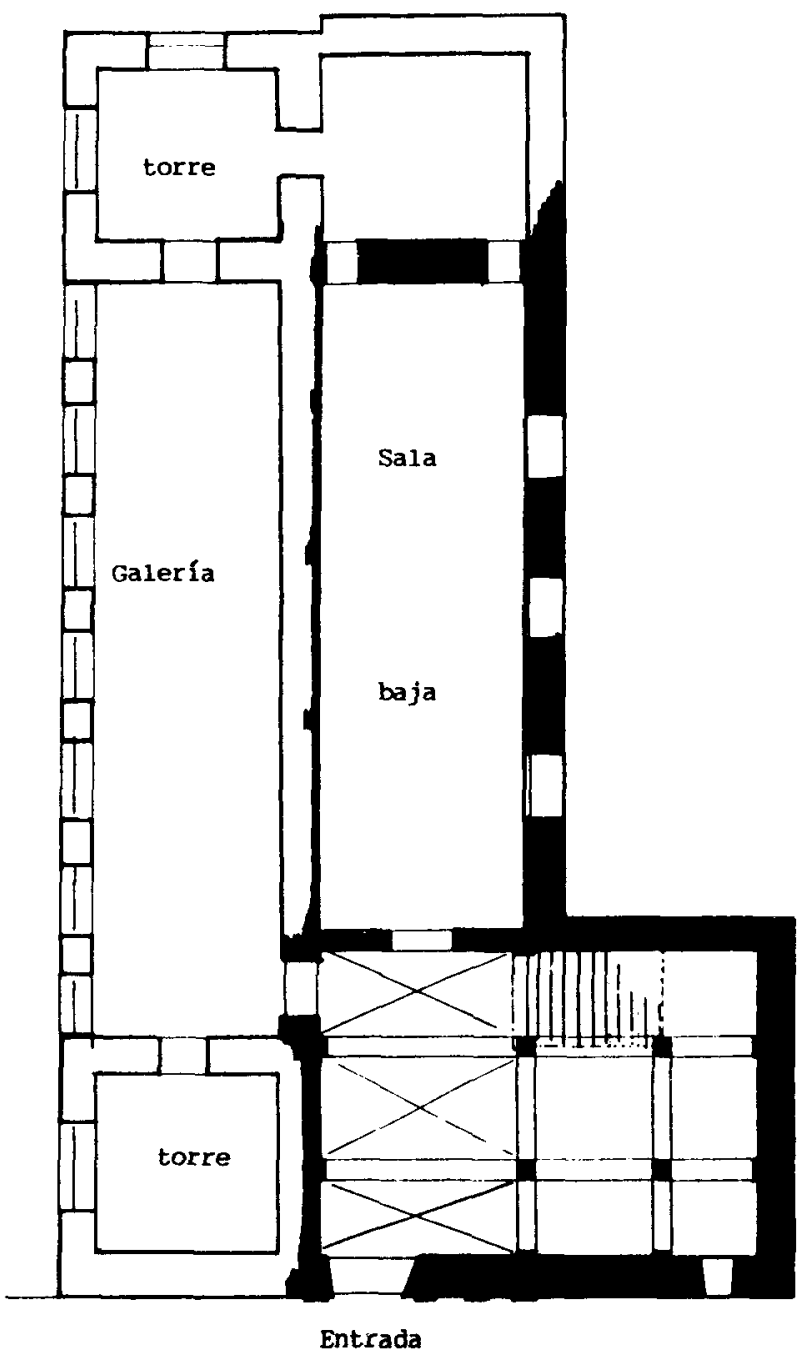

Fig. 9. Planta inferior de calle.

grado este sentido ornamental que también se hace expresivo en su capilla, embebida en la edificación general, pero encerrando un espacio religioso arquitectónicamente autónomo donde el efecto de verticalidad contrarresta la horizontalidad del espacio civil contiguo. Sobre planta centralizada, cuatro arcos de medio punto levantan sobre pechinas una media naranja superada por gran linterna ciega (figs. 13 y 14). 


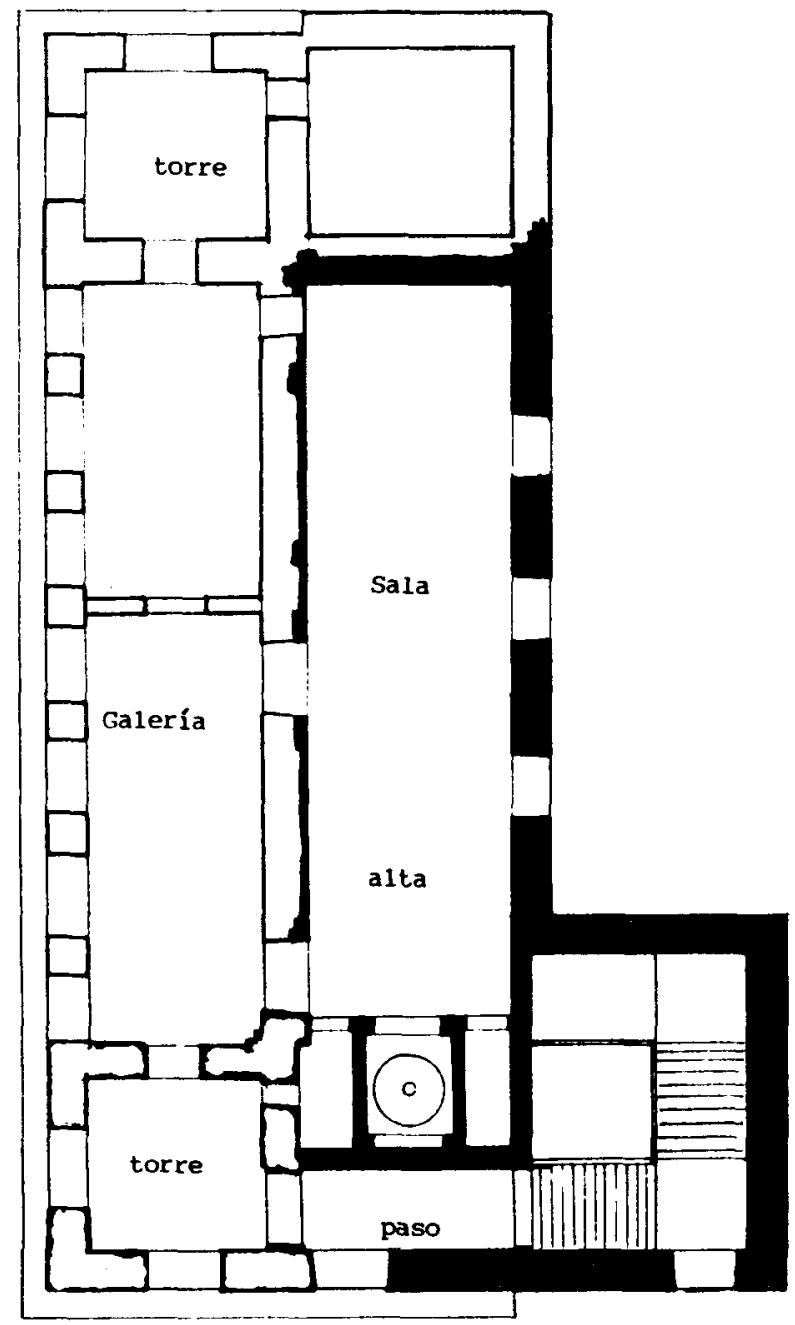

Fig. 10. Planta superior o principal.

Del proyecto de Ardemans para torres ochavadas, no realizado, se hubiera derivado un cambio radical en la percepción visual de la fachada principai que hubiera supuesto una suavización de la composición rectilínea de toda ella al ofrecer dos ejes verticales de menor efecto macizo. La maestría toledana revocó esta audaz iniciativa de sello barroco y en su lugar se levantó un doble cuerpo de torre cuadrada en la que el estilo arquitectónico se muestra deudor de la tradición estilística local y dentro 


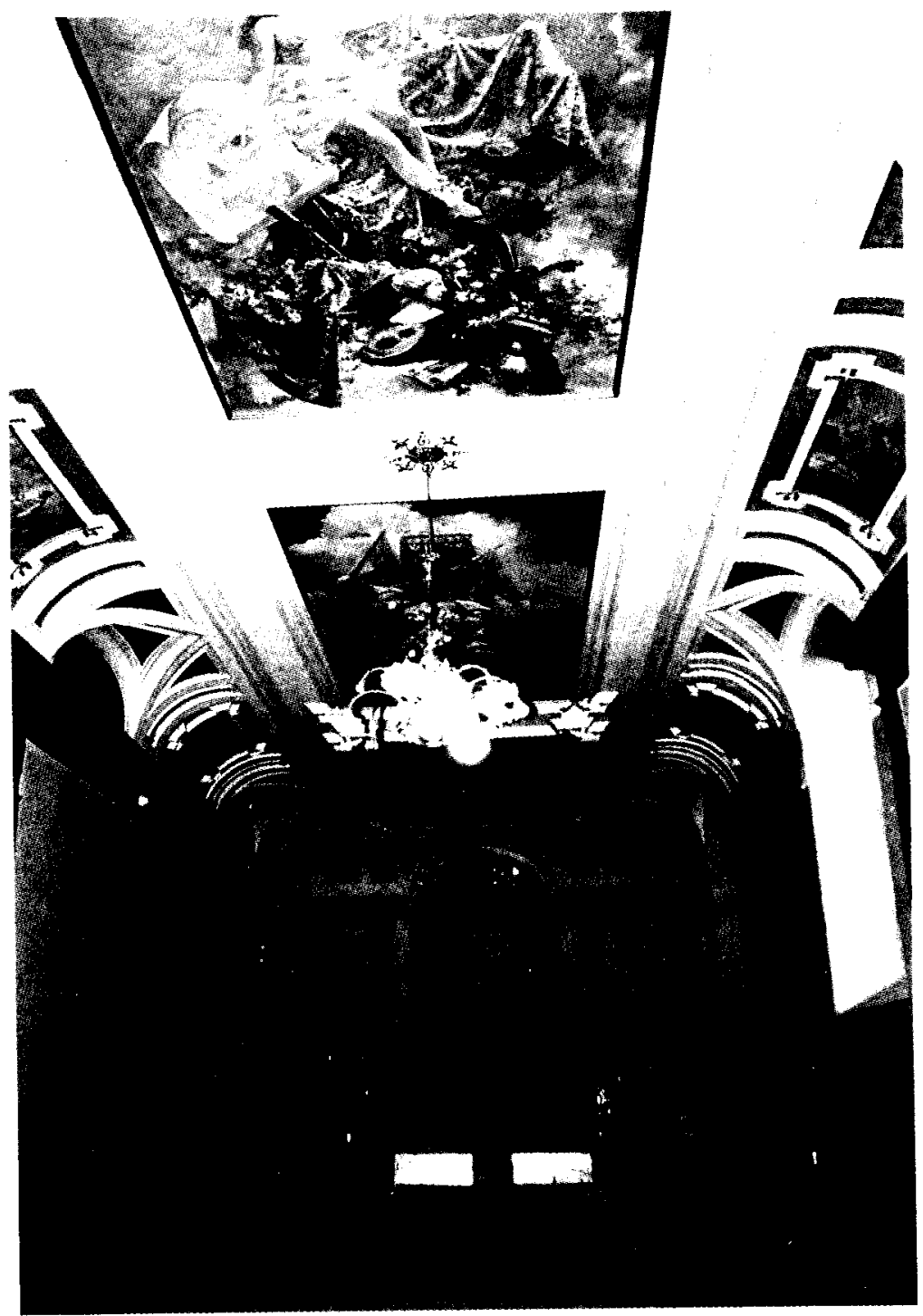

Fig. 11 Perspectiva de la sala baja. 


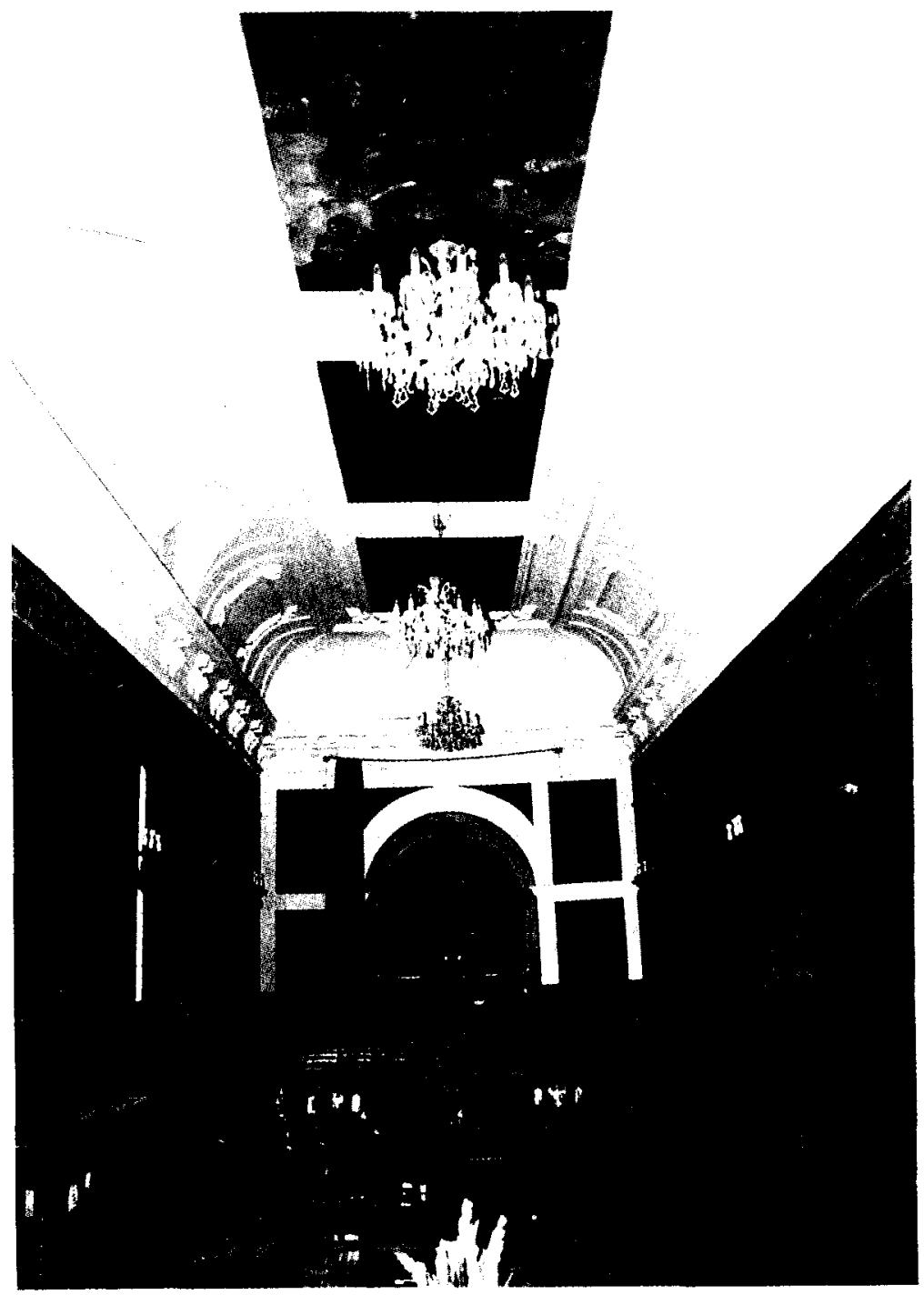

Fig. 12. Perspectiva de la sala alta. 


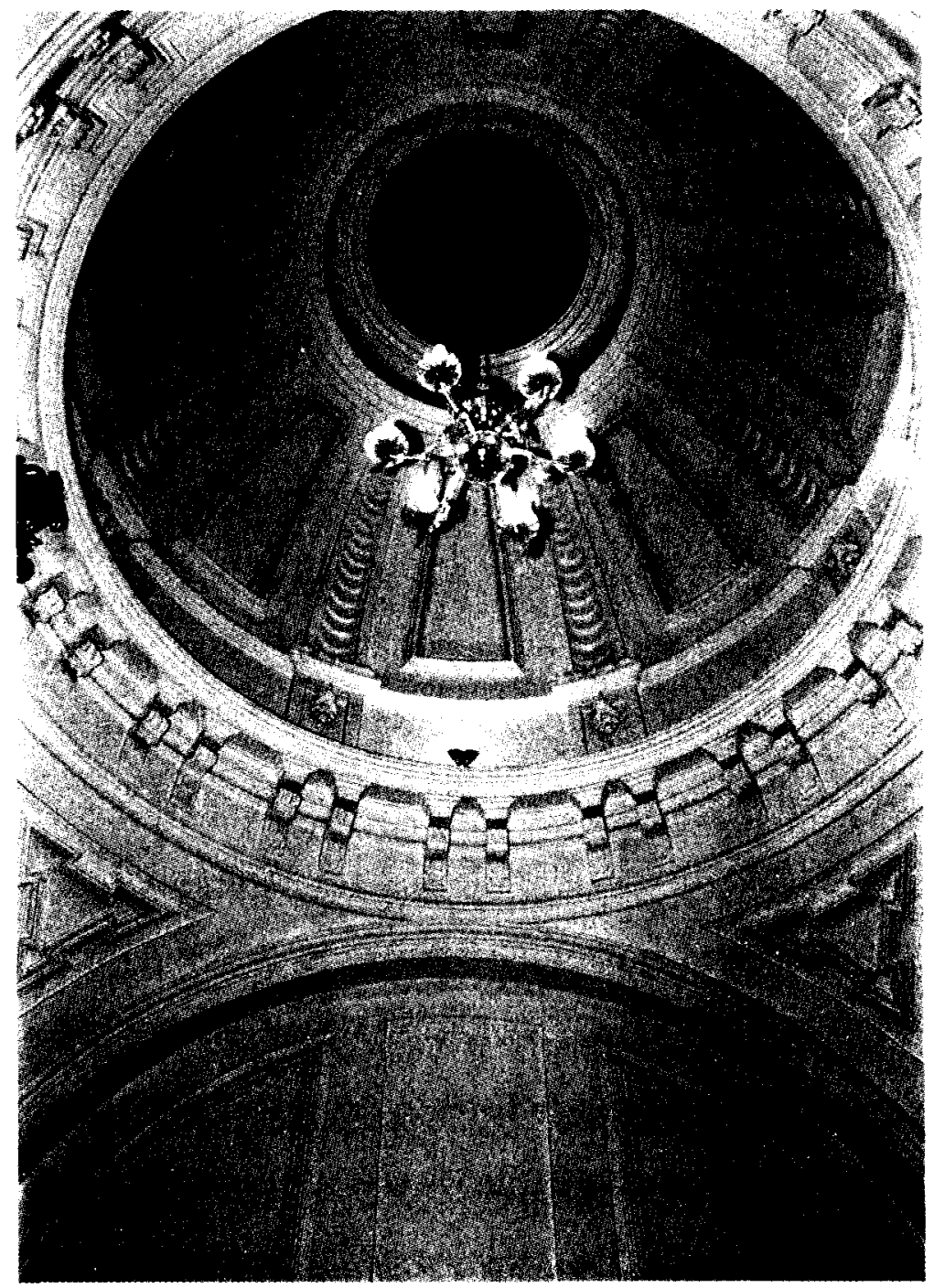

Fig. 13. Interior de la capilla.

de un barroco equilibrado y desornamentado. Pese a la aparente armonización con la fachada renacentista-manierista, las torres se desmarcan sutilmente de esta sujección a partir de la discontinuidad canónica de los elementos, de la articulación de los planos en los que el vano prevalece sobre las superficies sobrias y casi lisas, y de la progresiva disminución del volumen de los cuerpos con distintas soluciones en esquina. Pero, 



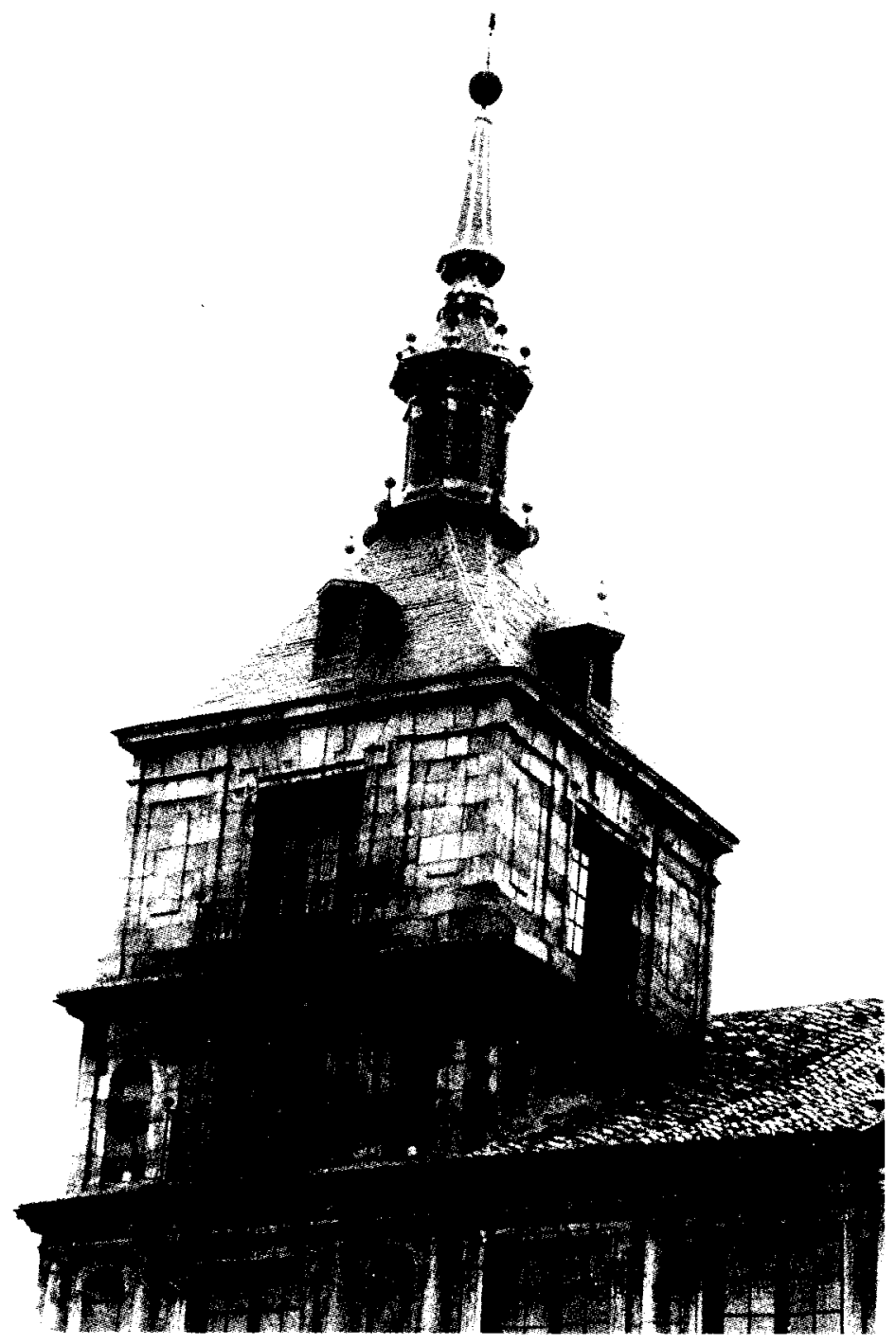

Fig. 15. Una de las torres barrocas. 